\title{
Mechanical properties of fire retardant wood-plastic composites: A review
}

\author{
T. C. Mokhena ${ }^{1}$, E. R. Sadiku1, M. J. Mochane ${ }^{2}$, S. S. Ray ${ }^{3,4}$ \\ ${ }^{1}$ Institute of Nano Engineering Research (INER), Department of Chemical, Metallurgical and Materials Engineering \\ (Polymer Technology Division), Tshwane University of Technology, Pretoria, South Africa \\ ${ }^{2}$ Department of Life Sciences, Central University of Technology Free State, Private Bag X20539, 9301 Bloemfontein, \\ South Africa \\ ${ }^{3}$ DST-CSIR, National Center for Nanostructured Materials, Council for Scientific and Industrial Research, 0001 Pretoria, \\ South Africa \\ ${ }^{4}$ Department of Applied Chemistry, University of Johannesburg, 2028 Doornfontein, Johannesburg, South Africa
}

Received 8 December 2020; accepted in revised form 11 February 2021

\begin{abstract}
Wood-plastic composites (WPCs) are a group of emerging and a sustainable class of high-performance materials, consisting of polymers reinforced with wood particulates, having a wide range of applications in the field of building, infrastructure, and transportation. However, the main drawback of the WPCs is their high flammability. Fire retardants usually enhance WPCs' flame retardancy but at the expense of mechanical properties. This paper reviews the available literature on flame retardant WPCs in developing an optimum condition between the flammability and mechanical properties, i.e., the addition of wood-flour and flame retardant (FR) in order to find a balance between the flammability resistance and their mechanical properties. It concentrates on the recent advances in the mechanical properties and flammability studies of wood flour-polymer composite products. The applications and durability of these flame retardant WPCs with future remarks are also highlighted.
\end{abstract}

Keywords: mechanical properties, flammability properties, polymer composites, wood-plastic composites, halogen-free flame retardants

Abbreviation
ABS
AEHOC
AHP
AP
APD-APP
APP
ASEA
AT
ATH
aveHRR
av-SEA
BC
BR
BX
$\mathrm{Ca}_{2} \mathrm{~B}_{6} \mathrm{O}_{11} \cdot 5 \mathrm{H}_{2} \mathrm{O}$
$\mathrm{CaCO}_{3}$

acrylonitrile-butadiene-styrene

average effective heat of combustion

aluminum hydrogen phosphate

aluminum phosphinate

glycerin-decorated APP

ammonium polyphosphate

average specific extinction area

antimony trioxide

aluminum hydroxide

average heat release rate

smoke extinction area

bamboo charcoal

decabromodiphenyl oxide

borax

$\mathrm{CaCO}_{3}$

colemanite

calcium carbonate
$\mathrm{CB}$

$\mathrm{CF}$

CNCs

CNTs

DAP

DFT

DOPO

DPER

DPER

EG

EHOC

ETA

FAR

FGI

FIGRA

F-lignin

FR carbon black

carbon fiber

cellulose nanocrystals

carbon nanotubes

diammonium phosphate

drip flame time

9,10-dihydro-9-oxa-10-phosphaphenanthrene-

10-oxide

dipentaerythritol

dipentaerythritol

expanded graphite

effective heat of combustion

ethanolamine

Aviation Regulation requirement

fire growth index

fire growth rate index

functionalized lignin

flame retardants

${ }^{*}$ Corresponding author, e-mail: mokhenateboho@gmail.com

C BME-PT 


\begin{tabular}{|c|c|}
\hline GNPs & graphene nanoplatelets \\
\hline HDPE & high density polyethylene \\
\hline HRR & heat release rate \\
\hline IFR & intumescent flame-retardant \\
\hline LDPE & low density polyethylene \\
\hline LMD & lignin-based flame retardant \\
\hline LOI & limited oxygen index \\
\hline MA- $g$-PE & maleic anhydride-grafted-polyethylene \\
\hline MA-g-PP & maleic anhydride-grafted-propylene \\
\hline MCA & melamine cyanurate \\
\hline $\mathrm{MD}$ & manganese oxide \\
\hline MDI & 4,4'-diphenylmethane diissocyanate \\
\hline MEL & melamine \\
\hline $\mathrm{Mg}_{3} \mathrm{Si}_{4} \mathrm{O}_{10}(\mathrm{OH})_{2}$ & Talc \\
\hline MH & magnesium hydroxide \\
\hline ML & mass loss \\
\hline MLR & mass loss rate \\
\hline MMT & montmorillonite \\
\hline MOE & modulus of elasticity \\
\hline MOR & modulus of rupture \\
\hline MP & melamine phosphate \\
\hline MUF & melamine-formaldehyde \\
\hline MWCNTs & multi-walled carbon nanotubes \\
\hline $\mathrm{Na}_{2} \mathrm{~B}_{4} \mathrm{O}_{7} \cdot 5 \mathrm{H}_{2} \mathrm{O}$ & tincalcinite \\
\hline $\mathrm{NaCaB}_{5} \mathrm{O}_{9} \cdot 8 \mathrm{H}_{2} \mathrm{O}$ & ulexite \\
\hline $\mathrm{OP}$ & aluminum diethyl phosphinate \\
\hline $\mathrm{Ph}$ & phytic acid \\
\hline PA & polyamides \\
\hline PE & polyethylene \\
\hline PET & poly(ethylene terephthalate) \\
\hline $\mathrm{Ph}-\mathrm{LDHs}$ & phytic acid-modified layered double hydroxides \\
\hline pHRR & peak heat release rate \\
\hline PMMA & polymethyl methacrylate \\
\hline PP & polypropylene \\
\hline PTPA & $\begin{array}{l}\text { poly[N4-bis(ethylenediamino)-phenyl phospho- } \\
\text { nic- } N 2, N 6 \text {-bis(ethylenediamino)-1,3,5-triazine- } \\
N \text {-phenyl phosphonate] }\end{array}$ \\
\hline $\mathrm{PVC}$ & polyvinyl chloride \\
\hline PVOH & poly(vinyl alcohol) \\
\hline $\mathrm{RP}$ & red phosphorus \\
\hline $\mathrm{SiO}_{2}$ & silica \\
\hline SWCNTs & single walled-carbon nanotubes \\
\hline TD & stannic oxide \\
\hline TFT & total flame time \\
\hline TGIC & triglycidyl isocyanurate \\
\hline THR & total heat release \\
\hline $\mathrm{TiO}_{2}$ & titanium oxide \\
\hline TPP & triphenyl phosphate \\
\hline TSP & total smoke production \\
\hline TTI & time-to-ignition \\
\hline WF & wood fiber \\
\hline WPC & wood-plastic composites \\
\hline $\mathrm{WPC}_{\mathrm{H}-\mathrm{CCB}}$ & honeycomb-like CB network \\
\hline $\mathrm{WP}_{\mathrm{CU}-\mathrm{CCB}}$ & uniformly-distributed WPC \\
\hline ZB & zinc borate \\
\hline
\end{tabular}

\section{Introduction}

For centuries, wood has been used in a wide variety of applications, which include the construction, mining, and building sectors, owing to its unique features, such as abundant availability, low cost, and excellent mechanical properties [1]. Microbial growth on wood surfaces and high water moisture absorption have been the major drawbacks that require frequent service to protect and maintain its valuable properties and thus, increasing the price of the wood product [2]. Nowadays, wood is combined or coated with polymeric materials for protection against microbial growth and to eliminate moisture absorption. The resulting products exhibit resistance to microbial growth and moisture absorption and hence, protect wood [3]. Often, these products are realized by improved properties, such as long-term performance, cost-effectiveness, and 'low carbon footprint', while offering the opportunity to fabricate various shapes for different applications. On the other hand, wood industries generate a lot of waste, which is often employed in energy generation or dumped in the landfills, which adversely affect the environment. The suitable solution is to mix polymeric materials with wood waste to manufacture an advanced generation of material known as 'wood-plastic composites (WPCs)'. This mixture can be, processed by using conventional polymer processing techniques, which afford their utilization in a wide range of structural and nonstructural applications with their different visual properties, including decking, automotive, construction, and housewares $[1,3,4]$.

Mechanical properties are frequently used engineering properties to establish WPCs application for structural and non-structural applications. Strength and elastic properties serve as primary criteria in selecting the design or product specifications. Therefore, knowledge on the mechanical properties of WPCs is important in both non-structural and structural applications. Similar to other composite materials, WPCs mechanical properties are often dependent on a number of factors, viz. weight fraction of components, type of additives, and fabrication process. WPCs often consist of other additives in order to enhance the processing and overall performance of the resulting products for them to qualify for the intended application [5]. These additives include coupling agents, light stabilizers, lubricants, pigments, antifungal, and foaming agents, with their formulation depend on the manufacturer and/or producers. In most cases, a large amount of WFs is often associated with the addition of zinc borate as an additive in order to improve the antifungal property. In some cases, UV stabilizers and/or gray pigments are included in WPCs composition to overcome issues associated with their lightening during outdoors 
service [5]. These additives influence the overall properties of the WPCs. Among these additives, flame retardants are usually added into WPCs in order to improve the fire performance of WPCs, especially for furniture and residential building applications $[1,4,6]$. It has been recognized that there is a trade-off between the flammability resistance and mechanical properties of the WPCs [7]. In addition, the poor compatibility between wood and polymeric matrix negatively affects the overall properties of the resulting WPC product. As a result, there is a need to overcome the limitations of WPCs in order to improve the long-term service of these composites. It is, recognized that the incorporation of flame-retardants, such as ammonium polyphosphate (APP) or expanded graphite (EG) could improve the flame retardancy of WPC, however, at the expense of mechanical properties $[8,9]$.

The aim of this review is to give a comprehensive and up-to-date overview of the latest literature on halogen-free FRs and their effect on the flammability of wood-plastic composites (WPCs). Recent progress that has been made to optimize the flame retardancy of WPC without compromising the mechanical properties of the resulting WPC product is also discussed. The poor interfacial adhesion between wood fiber and polymeric materials can be resolved by including a compatibilizer or by chemically treating the wood fibers [10]. In the case of compatibilizers, care must be taken such that the interaction between the compatibilizer and the FRs is minimal and thus, it cannot partake and/or compromise the interaction between the polymeric material and WFs. On the other hand, chemical treatment of the fibers has to be chosen such that some components of the fibers, which are important with regard to flame retardancy (e.g., lignin), are not fully removed from the fibers. Yang et al. [10] oxidized wood fibers (WFs) with hydrogen peroxide (as an oxidant) and $\mathrm{CuSO}_{4}$ (as the catalyzer) and found that oxidation of WFs improved their dispersion and interfacial adhesion with a hydrophobic polymer, poly(lactic acid) PLA. This resulted in an increase in the elongation-at-break even in the presence of flame retardant, i.e., 10\% APP. Therefore, this overview covers all the aspects that influence both mechanical and flame retardancy properties of WPC in the presence of flame retardant material as additive.

\subsection{Brief history of wood polymer composites}

The concept of wood-plastic composites (WPCs) was introduced in the 1970s in Italy, and they became popular in North America in the 1990s and later extended to the Asian countries in the $21^{\text {st }}$ century. As its name suggests, WPC is a unique product emanating from the blending of wood particulates with either thermosetting or thermoplastic polymers, either biodegradable or non-biodegradable [10]. For a better understanding of the history behind WPCs, Table 1 depicts the year-wise development of WPCs [11-14]. Different processing techniques, from traditional preparation methods (viz: thermoforming, extrusion, compression molding, hand lay-up, injection molding) to advanced manufacturing techniques (i.e., 3D printing), are generally employed to fabricate fascinating products, having different shapes

Table 1. Brief advancement in WPCs $[11,16]$.

\begin{tabular}{|c|c|}
\hline Year & Nature of advancements \\
\hline $1970-1973$ & $\begin{array}{l}\text { WPCs Concept was introduced with Gruppo Ovattifici Riunitti (GOR) fabricated what is called 'woodstock' for Fiat cars, } \\
\text { and Sonneson AB developed PVC-based WPCs towards floor tiles }\end{array}$ \\
\hline 1980 & WPCs were facing limited commercial exposure due to unfamiliarity between the wood and plastic industry \\
\hline 1983 & $\begin{array}{l}\text { Automotive interior components were manufactured by American Woodstock using Italian extrusion technology from } \\
50 \% \mathrm{PP} \text { and } 50 \% \text { WFs. }\end{array}$ \\
\hline 1990 & $\begin{array}{l}\text { Advanced Environmental Recycling Technology (AERT) and Mobil Chemical Company' division (which later became } \\
\text { Trex) manufactured WPCs from 50\% WF and polyethylene for deck boards, landscape timbers, picnic tables and industrial } \\
\text { flooring Strandex Corporation developed WPCs having different shapes without milling }\end{array}$ \\
\hline 1991 & $\begin{array}{l}\text { A rapid increase in WPC activities from research and industries, which led to the first international conference held in } \\
\text { Wisconsin, USA, to facilitate collaboration between active industries and researchers }\end{array}$ \\
\hline 1993 & PVC-based WPC for door profiles and window frames were developed by Andersen Corporation \\
\hline 1996 & $\begin{array}{l}\text { The division into active pelletized feedstock from wood or other natural fibers and plastic (i.e., WPC compound) for } \\
\text { processors to produce different components }\end{array}$ \\
\hline $2003-2015$ & Rapid WPC market with building industry being the biggest end-user, followed by automotive interior and furniture \\
\hline Today-present & $\begin{array}{l}\text { The advancements resulted in the largest and fastest marketing growing market, decking with research concentrating } \\
\text { on introducing various additives to open new avenues for WPCs } \\
\text { In the case of FRs as additives, new directions to incorporate eco-friendlier FRs from natural resources }\end{array}$ \\
\hline
\end{tabular}


and sizes [12-14]. The resulting products feature unique properties, such as recyclability, high specific properties, good mechanical properties, and thermal properties. They require less maintenance, and their moldability into different shapes and sizes makes these materials to be applicable in different fields, such as construction, automotive, furniture, optoelectronic devices, and many others [15]. WPCs, however, have some disadvantages that prevent their broad applications in certain advanced fields that include limited flammability properties as well as poor dispersion and lack of interfacial adhesion with a hydrophobic polymer, which adversely affect the ensuing properties. In the case of poor compatibility, various coupling agents and/or compatibilizers have been employed to improve fibers dispersion and interfacial adhesion between WFs and the host polymers, as explained in the introduction section. On the other hand, most of the WPC materials must be, subjected to a regulatory fire test to give the public an assurance of the material's safety. The improvement in flammability resistance of WPC has become an important issue since they have been applied in various fields, especially for residential construction and furniture. However, it is recognized that the presence of flame-retardants (FRs) affects the interaction between WFs and the host polymeric materials, hence adversely affecting the resulting overall properties.

\subsection{Flame retardants (FRs)}

FRs can broadly be categorized into halogenated FRs (which will not be discussed in this review), metal hydroxide (metal hydrates), and phosphoruscontaining products $[16,17]$. Other FRs include smoking suppressants and nanofillers. Nanofillers are often considered excellent FRs due to their unique features, viz: high aspect ratio, good mechanical properties, excellent thermal stability, which improve the overall mechanical and physical properties of the resulting materials. Since the inclusion of FRs into WPCs, often lead to the deterioration of mechanical properties due to the amount of FRs required in order to achieve the desired fire performance, nanofillers are considered as suitable alternatives to improve the non-flammability of WPCs without negatively affecting the mechanical properties of the resulting WPC products. Besides that, research has escalated in finding a balance between the fire performance and physical/mechanical properties.
In order to enhance the flammability resistance of WPC, a number of flame retardant (FR) materials are, added to the WPC systems [7, 17, 18]. It is wellknown that intumescent technology is capable of providing fire protection for flammable materials. There are three well-known active ingredients for intumescent formulations, i.e., an acid source as a catalyst, a carbonization compound, and a blowing agent $[16,17]$. A general mechanism of an intumescent flame retardant material is such that a highly flameretardant material forms a char during heating, acting as a physical barrier on the surface of the highly flammable material (see Figure 1). This slows down the heat from entering the substrate and hence, the removal of volatile materials from the substrate into the flame and, as a result, flammability resistance will be enhanced.

The most efficient compounds for flame resistance application contain a single or a combination of these elements: bromine, chlorine, and phosphorus [7, 17]. Yet, other elements with flame resistance properties are boron, nitrogen, antimony, zinc, silicon, and carbon. These elements are often bound to phosphorus or halogenated compounds; thus, flame retardants (FRs) are, in broad terms, classified into the halogenated and halogen-free fillers [19]. In the past, halogenated flame retardant materials were mostly employed due to their effectiveness in terms of improving the flame retardancy of most engineering plastics [19]. Recently, halogenated flame retardant fillers were banned due to the release of toxic gases during burning. In order to solve the problem of halogenated fillers, more halogen-free flame retardant fillers were introduced to replace the halogenated group. Recent research studies have shown that the intumescent flame-retardant (IFR) materials have low toxicity and low smoke, which make them the flameretardants of choice for WPC. Over the past decades, many improvements have been accomplished by researchers to enhance the flammability resistance of WPC using halogen-free flame-retardants fillers.

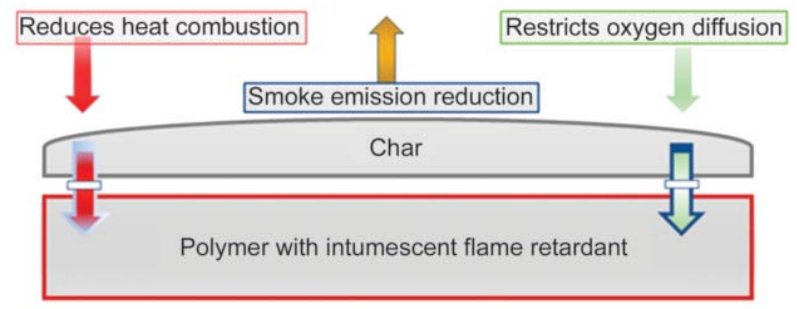

Figure 1. Demonstration of the action mechanism of an intumescent flame retardant. 
Hence, the aim of this review is limited to the discussion of the halogen-free flame-retardant fillers as inclusions into WPC systems. Since there is a tradeoff between flame retardancy improvement and the mechanical properties of the resulting composites, a further perspective/look into the influence of these fillers on their resulting WPCs mechanical properties was undertaken.

\section{WPCs fabrication}

The processing techniques depend on the polymeric material, which plays a critical role in the amount and type of FR used to achieve the desired flammability performance without compromising other properties, i.e., mechanical and physical properties [20]. Moreover, the selection of the processing techniques for the production of WPCs containing additives must meet some of the criteria such as durability, low manufacturing cost, production rate, size, and shape of the resulting composite products [21]. Table 2 presents a list of WPCs, containing different FRs with the processing techniques employed, the compatibilizers used as well as the highlights of the results obtained from these studies. Thermoplastic-based WPCs manufacturing involves two steps, i.e., compounding and forming [22]. Compounding consists of adding additives and WFs into polymer melt in order to obtain a homogeneous composite. Extrusion, compression molding and/or injection molding are widely used processing techniques to incorporate flame-retardants into thermoplastic-based WPC, and they can also be classified as either compounding or forming, as depicted in Table 2 [23-30]. Shaping consists of melting the compound and molding it to the desired end-product. In some cases, compounding and forming can be performed in a single step. These thermoplastics include the commodity-based, i.e., polyethylene (PE), polypropylene (PP), polymethyl methacrylate) (PMMA), polyvinyl chloride (PVC) and poly (ethylene terephthalate (PET) and the engineering types, e.g., acrylonitrile-butadiene-styrene (ABS), polyamides (PA), and poly(vinyl alcohol) $(\mathrm{PVOH})$ [31-33]. PP and PE are the most used polymers, not only because of their combustion that results in less toxic gases but also to their low melting temperatures, which are well below the degradation temperature of wood fibers $[25,34,35]$. Yet, another commonly used polymer is PVC, with good flame-resistance properties, but the release of toxic gases during combustion has been its limiting factor in WPCs manufacturing [36]. Different compatibilizers or coupling agents are usually incorporated to promote adhesion between WFs and host polymeric materials. Commonly grafted compounds include the maleic anhydride grafted to polymers, e.g., maleic anhydride-grafted-polyethylene (MA-g-PE), maleic anhydride-grafted-propylene (MA- $g$-PP), and silanebased compounds [17]. Ammonium phosphate and graphite are two of the most commonly utilized flame retardants, in addition to metal hydroxides, e.g., aluminum hydroxide and magnesium hydroxide, due to their high efficiency in fire resistance [37]. Solution casting was also reported as an alternative technique for the fabrication of WPCs [38-41]. Thermosetsbased WPCs have also been reported in the literature $[42,43]$. In this case, the conventional processing methods for thermosets-based composites, which include: melt compression or sheet molding compound, hand lay-up, resin transfer molding, pultrusion, vacuum-assisted resin transfer molding, are also employed [26, 42-45].

\section{Flammability properties}

Wood consists of cellulose, hemicellulose, lignin, and other extractives [46], with some decomposing at a temperature below $150^{\circ} \mathrm{C}$. As such, the sample surface can be heated-up to $150^{\circ} \mathrm{C}$ within the first $25 \mathrm{~s}$ during a cone calorimetry test, which leads to decomposition that is often represented by a small peak in the pHRR curve below 30 seconds. Since the decomposition of the WPC depends on the contents, formulation, and the degree of dispersion and/or interfacial adhesion of the compounds in the system, the resulting flame retarding efficiency is completely different for each system [47-50]. Besides the content of the flame retardant filler content is one of the decisive parameters, the use of compatibilizers in order to improve the interaction between the flameretardant filler and WPC, as well as the dispersion, was also found to improve the overall flame resistance efficiency of the resulting product [51].

In general, wood has low specific heat $(1.2 \mathrm{~kJ} /(\mathrm{kg} \cdot \mathrm{K})$ when compared to polymers $(1.5-1.7 \mathrm{~kJ} /(\mathrm{kg} \cdot \mathrm{K}))$ as well as its decomposition temperature. Furthermore, wood has less heat release rate, which in turn suppresses the burning rate of WPCs at higher WF content (40-60 wt\%) [52]. The presence of wood drastically decreases the amount of FRs often used to achieve the desired flame resistance properties (see Table 3). $20 \mathrm{wt} \%$ and above of FRs, is usually 
Table 2. List of WPCs containing different FRs, their processing techniques and the corresponding compatibilizers used for the production of the WPCs.

\begin{tabular}{|c|c|c|c|c|}
\hline Formulation & Processing technique & Compatibilizer & Highlights & Refs. \\
\hline WF/PVC/Clay & $\begin{array}{l}\text { Melt compounding (twin- } \\
\text { screw extruder) }\end{array}$ & $\begin{array}{l}\text { Aminopropyl- } \\
\text { methyldiethoxys } \\
\text { ilane }\end{array}$ & $\begin{array}{l}\text { - Silane treatment of the wood fiber resulted in improv- } \\
\text { ing the overall mechanical properties, which further } \\
\text { increased by the presence of clay. } \\
\text { - The flame retardancy performance was enhanced by } \\
\text { adding the presence of clay at relatively low content } \\
\text { (i.e., below } 1.5 \mathrm{wt} \% \text { ) }\end{array}$ & [27] \\
\hline $\begin{array}{l}\text { HDPE/WF/magnesium } \\
\text { hydroxide }(\mathrm{MH})\end{array}$ & \multirow{3}{*}{ Twin-screw extruder } & \multirow{3}{*}{-} & \multirow{3}{*}{$\begin{array}{l}\text { - APP-based composites displayed the greatest flame } \\
\text { retardancy efficiency compared to other FRs; more- } \\
\text { over, OI increased by } 29 \% \text {; but MH showed increased } \\
\text { TTI by } 24 \% \\
\text { - ZB exhibited excellent mechanical properties (flexural } \\
\text { strength increased by } 21 \% \text { and Flexural modulus of } \\
\text { elasticity by } 14 \% \text { ) }\end{array}$} & \multirow{3}{*}[6]{} \\
\hline $\begin{array}{l}\text { HDPE/WF/zinc borate } \\
\text { (ZB) }\end{array}$ & & & & \\
\hline $\begin{array}{l}\text { HDPE/WF/melamine } \\
\text { phosphate (MP) }\end{array}$ & & & & \\
\hline HDPE/WF/APP & \multirow{6}{*}{ Two roll } & \multirow{6}{*}{ MA-g-PE } & \multirow{6}{*}{$\begin{array}{l}\text { APP exhibited superior LOI when compared to all inves- } \\
\text { tigated samples, with no significant effect on the me- } \\
\text { chanical properties }\end{array}$} & \multirow{6}{*}[7]{} \\
\hline LDPE/WF/APP & & & & \\
\hline LDPE/WF/MP & & & & \\
\hline LDPE/WF/PER & & & & \\
\hline LDPE/WF/APP/PER & & & & \\
\hline LDPE/WF/MP/APP & & & & \\
\hline $\begin{array}{l}\text { HDPE/WF/hypophospho- } \\
\text { rous acid-based ionic liq- } \\
\text { uid, }[\mathrm{Bmim}] \mathrm{H}_{2} \mathrm{PO}_{2}(\mathrm{BMP})\end{array}$ & \multirow{3}{*}{$\begin{array}{l}\text { Melt compounding fol- } \\
\text { lowed by melt pressing }\end{array}$} & \multirow{3}{*}{ MA- $g$-HDPE } & \multirow{3}{*}{$\begin{array}{l}\text { Positive synergy effect between EG and ionic liquid re- } \\
\text { sulted in enhanced flame retardancy of the composite } \\
\text { product }\end{array}$} & \multirow[t]{3}{*}[28]{} \\
\hline HDPE/WF/EG & & & & \\
\hline HDPE/WF/BMP/EG & & & & \\
\hline HDPE/WF & \multirow{4}{*}{$\begin{array}{l}\text { Twin-screw extruder fol- } \\
\text { lowed by injection mold- } \\
\text { ing }\end{array}$} & \multirow{4}{*}{-} & \multirow{4}{*}{$\begin{array}{l}\text { - BX performed better than other samples with regard } \\
\text { to mechanical and flame retardancy }\end{array}$} & \multirow{4}{*}[32]{} \\
\hline HDPE/WF/BA & & & & \\
\hline HDPE/WF/BX & & & & \\
\hline HDPE/WF/BA/BX & & & & \\
\hline $\mathrm{PP} / \mathrm{WF} / \mathrm{ZB}$ & \multirow{4}{*}{ Melt pressing } & \multirow{4}{*}{ MA-g-PP } & \multirow{4}{*}{$\begin{array}{l}\text { - The increase in WF content led to enhance flame-re- } \\
\text { tarding property at the expense of mechanical proper- } \\
\text { ties. } \\
\text { - ZB exhibited better mechanical and physical proper- } \\
\text { ties, followed by MH, and APP. } \\
\text { - APP was most effective FR to reduce peak HRR and } \\
\text { HRR. }\end{array}$} & \multirow{4}{*}{ [29] } \\
\hline $\mathrm{PP} / \mathrm{WF} / \mathrm{BR}$ & & & & \\
\hline $\mathrm{PP} / \mathrm{WF} / \mathrm{MH}$ & & & & \\
\hline PP/WF/APP & & & & \\
\hline $\begin{array}{l}\mathrm{PP} / \mathrm{WF} / \text { aluminum phos- } \\
\text { phinate }(\mathrm{AP}) / \text { melamine } \\
\text { cyanurate (MCA) }\end{array}$ & Melt pressing & MA-g-PP & $\begin{array}{l}\text { AP/MCA (5:1) with } 20 \% \text { loading exhibited balanced me- } \\
\text { chanical and flame resistance. The latter was due to a } \\
\text { combination of gas-phase and condensed-phase flame } \\
\text { resistance during burning and thick P-O-C cross-linked } \\
\text { char layer which hindered heat and flammable gases } \\
\text { transfer into the underneath materials. }\end{array}$ & {$[22]$} \\
\hline $\mathrm{PP} / \mathrm{WF} / \mathrm{MH}$ & \multirow{3}{*}{ Twin-screw extruder } & \multirow{3}{*}{ MA-g-PP } & \multirow{3}{*}{$\begin{array}{l}\text { EG showed better fire performance and good smoke sup- } \\
\text { pression }\end{array}$} & \multirow{3}{*}[34]{} \\
\hline $\mathrm{PP} / \mathrm{WF} / \mathrm{EG}$ & & & & \\
\hline PP/WF/APP & & & & \\
\hline $\mathrm{PP} / \mathrm{WF}$ & \multirow{8}{*}{$\begin{array}{l}\text { Injection molding and } \\
\text { melt-pressing }\end{array}$} & \multirow{8}{*}{-} & \multirow{8}{*}{$\begin{array}{l}\text { - The decoration of APP resulted in good fire perform- } \\
\text { ance with improved mechanical properties when com- } \\
\text { pared to APP-containing WPC and neat WPC. } \\
\text { - WPC containing } 30 \mathrm{wt} \% \text { WPC performed better than } \\
\text { other samples, but the expensiveness of amino glyc- } \\
\text { erin makes this system not suitable for WPC/FRs sys- } \\
\text { tems }\end{array}$} & \multirow{8}{*}[35]{} \\
\hline PP/WF/APP & & & & \\
\hline PP/WF/APP & & & & \\
\hline PP/WF/APP & & & & \\
\hline $\begin{array}{l}\text { PP/WF/glycerin decorated } \\
\text { APP (ADP-APP) }\end{array}$ & & & & \\
\hline PP/WF/ADP-APP & & & & \\
\hline PP/WF/ADP-APP & & & & \\
\hline PP/WF/ADP-APP & & & & \\
\hline
\end{tabular}


Table 2. Continuous.

\begin{tabular}{|c|c|c|c|c|}
\hline Formulation & Processing technique & Compatibilizer & Highlights & Refs. \\
\hline PLA/WF & \multirow{2}{*}{$\begin{array}{l}\text { Twin roll mill followed by } \\
\text { hot-pressing }\end{array}$} & \multirow{2}{*}{$\begin{array}{l}\text { 3-aminopropyl- } \\
\text { triethoxysilane } \\
\text { (KH550) }\end{array}$} & \multirow{2}{*}{$\begin{array}{l}\text { Composite passed UL-94 V-0 with the incorporation of } \\
15 \% \text { PA treated WFs }\end{array}$} & \multirow{2}{*}{ [30] } \\
\hline PLA/WF/phytic acid (Ph) & & & & \\
\hline $\begin{array}{l}\mathrm{HDPE} / \mathrm{PVC} / \mathrm{PCL} / / \mathrm{WF} / \\
\mathrm{APP}\end{array}$ & \multirow{3}{*}{$\begin{array}{l}\text { Twin-screw extrusion fol- } \\
\text { lowed by melt-pressing }\end{array}$} & \multirow{3}{*}{-} & \multirow{3}{*}{$\begin{array}{l}\mathrm{SiO}_{2} \text {-based WPC exhibited the best overall properties } \\
\text { (flame retardancy and mechanical properties) }\end{array}$} & \multirow{3}{*}[25]{} \\
\hline $\begin{array}{l}\mathrm{HDPE} / \mathrm{PVC} / \mathrm{PCL} / \mathrm{WF} / \\
\mathrm{APP} / \mathrm{PER}\end{array}$ & & & & \\
\hline $\begin{array}{l}\mathrm{HDPE} / \mathrm{PVC} / \mathrm{PCL} / / \mathrm{WF} / \\
\mathrm{APP} / \mathrm{PER} \text { filled with ei- } \\
\text { ther } \mathrm{SiO}) \text { one } \mathrm{CaCO}_{3}\end{array}$ & & & & \\
\hline $\mathrm{PS} / \mathrm{WF} / \mathrm{BA}$ & $\begin{array}{l}\text { Melt mixing followed by } \\
\text { melt pressing }\end{array}$ & - & $\begin{array}{l}\text { Mechanical properties were directly dependent on the } \\
\text { BA content }\end{array}$ & {$[33]$} \\
\hline $\begin{array}{l}\text { Melamine-formaldehyde } \\
\text { (MUF) with 10,15, 20\% } \\
\text { of melamine/WF/BA }\end{array}$ & \multirow{6}{*}{ Melt pressing } & \multirow{6}{*}{-} & \multirow{6}{*}{$\begin{array}{l}\text { Boron-based FRs negatively affected modulus of rupture } \\
\text { (MOR) and internal bond strength of which were coun- } \\
\text { teracted by increase in melamine content in MUF resin }\end{array}$} & \multirow{6}{*}[26]{} \\
\hline $\begin{array}{l}\text { Melamine-formaldehyde } \\
\text { (MUF) with 10,15,20\% } \\
\text { of melamine/WF/BX }\end{array}$ & & & & \\
\hline $\begin{array}{l}\text { Melamine-formaldehyde } \\
\text { (MUF) with } 10,15,20 \% \\
\text { of melamine/WF/sodium }\end{array}$ & & & & \\
\hline $\begin{array}{l}\text { Melamine-formaldehyde } \\
\text { (MUF) with } 10,15,20 \% \\
\text { of melamine/WF/ZB }\end{array}$ & & & & \\
\hline $\begin{array}{l}\text { Melamine-formaldehyde } \\
\text { (MUF) with } 10,15,20 \% \\
\text { of melamine/WF/BA+BX }\end{array}$ & & & & \\
\hline $\begin{array}{l}\text { Melamine-formaldehyde } \\
\text { (MUF) with 10,15, 20\% of } \\
\text { melamine/WF/BA+SPT }\end{array}$ & & & & \\
\hline
\end{tabular}

required in order to achieve self-distinguishable properties in thermoplastics [53, 54]. For example, $\sim 10 \mathrm{wt} \%$ of APP is required to produce self-extinguishing properties of WPC (but with a wood content being $>40 \mathrm{wt} \%$ ) [54].

\subsection{Metal hydroxides}

Metal hydroxide decomposition under heat involves an endothermic reaction that consumes heat, meanwhile releasing water to dilute the flammable gases (the fuel needed to sustain combustion under fire) in the gas phase [55-57]. They are environmentally friendly and capable of reducing the amount of toxic gases emitted, e.g., CO. The quantities of metal hydroxide required to achieve better fire performance are quite large, which can adversely affect mechanical properties. The most commonly employed metal hydroxide for WPCs is magnesium hydroxide; however, there are some studies based on aluminum hydroxide (ATH) [58]. For instance, Arao et al. [54] reported on the effect of aluminum hydroxide on the fire performance of WPCs. The burning rate of the WPCs decreased from 32.4 to $20.9 \mathrm{~mm} / \mathrm{min}$ in the presence of ATH. It was found that ATH increased time-to-ignition (TTI) (due to the high heat capacity of aluminum hydroxide) while decreasing the peak heat release rate (pHRR) and the total heat release (THR) by 67 and 15\%, respectively. Umemura et al. [56] reported that the inclusion of ATH into WPCs resulted in an increased TTI the most because of the high heat capacity of ATH. pHRR was decreased by $67 \%$ and THR by $15 \%$. Pham et al. [58] established the fact that $32 \mathrm{wt} \%$ ATH in WPC is sufficient enough to produce a composite that passed the UL-94 rating of $\mathrm{V}-\mathrm{0}$ without dripping during combustion. This is due to ATH acting in the condensed phase by providing a solid $\mathrm{Al}_{2} \mathrm{O}_{3}$ during burning, which prevented oxygen and heat invasion into the composite. Magnesium hydroxide (MH) has also been studied as a suitable FR for WPC. Despite MH being one of the best FRs for WPCs, it was found that the size of the particles can also influence its fire performance [55]. The best fire performance was reported for ultrafine MH (30\%), with pHRR decreasing by $48 \%$ and THR by $62 \%$, whereas TTI increased by $161 \%$ when compared to WPC without FRs due to its ability 
Table 3. Flame resistance properties for WPC.

\begin{tabular}{|c|c|c|c|c|c|c|c|c|}
\hline Formulation & $\begin{array}{c}\text { TTI } \\
{[\mathbf{s}]}\end{array}$ & $\begin{array}{c}\mathrm{pHRR} \\
{\left[\mathrm{kW} / \mathrm{m}^{2}\right]}\end{array}$ & $\begin{array}{c}\text { THR } \\
{\left[\mathrm{MJ} / \mathrm{m}^{2}\right]}\end{array}$ & TSP & $\begin{array}{l}\text { Char } \\
{[\%]}\end{array}$ & $\begin{array}{l}\text { LOI } \\
{[\%]}\end{array}$ & UL-94 & Refs. \\
\hline WF/PP/ PP-g-MA (50/46.7/3.3)-APP $11 \mathrm{phr}$ & 34 & 503 & 133 & 11 & 8.5 & 22.8 & NR & \multirow[b]{2}{*}[47]{} \\
\hline $\begin{array}{l}\text { APP/WF/PP/PP- } g \text {-MA/Ph-LDH } \\
(50 / 35.7 / 3.3 / 1)-\mathrm{APP} 10 \mathrm{phr}\end{array}$ & 25 & 285 & 91 & 13 & 27 & 23 & $\mathrm{~V}-0$ & \\
\hline $\mathrm{PP} / \mathrm{WF} / \mathrm{CA}^{\mathrm{a}}(65 / 30 / 5)$ & 12 & 701 & - & - & - & 21.4 & - & \multirow{4}{*}{ [49] } \\
\hline $\mathrm{PP} / \mathrm{WF} / \mathrm{CA}^{\mathrm{a}}(65 / 30 / 5)-\mathrm{APP} 20 \mathrm{phr}$ & 18 & 568 & - & - & - & 26.5 & - & \\
\hline $\mathrm{PP} / \mathrm{WF} / \mathrm{CA}^{\mathrm{a}}(65 / 30 / 5)-\mathrm{APP} 30 \mathrm{phr}$ & 18 & 505 & - & - & - & 27.4 & - & \\
\hline $\mathrm{PP} / \mathrm{WF} / \mathrm{CA}^{\mathrm{a}}(65 / 30 / 5)-\mathrm{APP}+\mathrm{SiO}_{2}(20+10 \mathrm{phr})$ & 32 & 428 & - & - & - & 28.9 & - & \\
\hline $\mathrm{PP} / \mathrm{WF}(50 / 50)$ & 14 & 491 & 107 & 15.6 & 26 & 19 & NR & \multirow{7}{*}[35]{} \\
\hline PP/WF/APP (40/40/20) & - & - & - & - & - & 21 & NR & \\
\hline $\mathrm{PP} / \mathrm{WF} / \mathrm{APP}(37 / 37 / 26)$ & 15 & 292 & 94 & 12.5 & 37 & 22 & NR & \\
\hline PP/WF/APP (35/35/30) & - & - & - & - & - & 25 & $\mathrm{~V}-0$ & \\
\hline $\begin{array}{l}\text { PP/WF/amino glycerine decorated APP } \\
(40 / 40 / 20)\end{array}$ & 13 & 231 & 87 & 8.3 & 38 & 23 & NR & \\
\hline $\begin{array}{l}\text { PP/WF/amino glycerine decorated APP } \\
(37 / 37 / 26)\end{array}$ & 15 & 185 & 82 & 5.0 & 40 & 29 & $\mathrm{~V}-0$ & \\
\hline $\begin{array}{l}\text { PP/WF/amino glycerine decorated APP } \\
(35 / 35 / 30)\end{array}$ & 16 & 147 & 82 & 3.7 & 41 & 36 & V0 & \\
\hline $\mathrm{PP} / \mathrm{WF}(50 / 50)$ & - & - & - & - & - & 18 & NR & \multirow{5}{*}[50]{} \\
\hline $\begin{array}{l}\text { PP/WF/aluminum hydrogen phosphonate } \\
\text { (AHP) }(35 / 35 / 30)\end{array}$ & - & - & - & - & - & 19 & NR & \\
\hline $\mathrm{PP} / \mathrm{WF} /$ triphenyl phosphate (TPP) $(35 / 35 / 30)$ & - & - & - & - & - & 21 & NR & \\
\hline PLA/WF/PEG (80/10/10) & 46 & 537 & 64.8 & - & 6.8 & 20.0 & NR & \\
\hline PLA/oxidized WF/PEG (80/10/10) & 43 & 522 & 62.0 & - & 9.0 & 21.0 & $\mathrm{~V}-2$ & \\
\hline PLA/oxidized WF/PEG (80/10/10)-APP $10 \mathrm{phr}$ & 40 & 280 & 53.5 & - & 18.4 & 30.6 & $\mathrm{~V}-0$ & \multirow{3}{*}[10]{} \\
\hline PLA/oxidized WF/PEG (80/10/10) & 43 & 522 & 62.0 & - & 9.0 & 21.0 & $\mathrm{~V}-2$ & \\
\hline PLA (100)-APP $10 \mathrm{phr}$ & 55 & 403 & 56.3 & - & 15.6 & 29.3 & $\mathrm{~V}-0$ & \\
\hline PP/WF/MAPP/Antioxidant 1010 36/54/9/1 & 23 & 507.2 & 128.3 & - & - & 23.8 & - & \multirow{4}{*}[22]{} \\
\hline $\begin{array}{l}\text { PP/WF/MAPP/Antioxidant 1010/AP } \\
\text { 28/42/9/1/20 }\end{array}$ & 32 & 347.5 & 108.3 & - & - & 27.7 & - & \\
\hline $\begin{array}{l}\text { PP/WF/MAPP/Antioxidant 1010/MCA } \\
\text { 28/42/9/1/20 }\end{array}$ & 37 & 443.9 & 122.0 & - & - & 27.2 & - & \\
\hline $\begin{array}{l}\text { PP/WF/MAPP/Antioxidant 1010/AP/MCA } \\
\text { 28/42/9/1/16.7/3.3 }\end{array}$ & 34 & 304.1 & 97.9 & - & - & 29.5 & $\mathrm{~V}-0$ & \\
\hline
\end{tabular}

${ }^{\mathrm{a}} \mathrm{CA}$ represent coupling agent (i.e., either maleic anhydride grafted styrene-ethylene-butylene-styrene (SEBS-g-MA) or maleic anhydridegrafted polypropylene (PP- $g$-MA)), NR = No rating

to form compact char layer, thereby acting as an insulator for heat and oxygen to protect and delay the decomposition [55]. Ordinary-sized MH exhibited 29 and 24\% reductions of pHRR and THR, respectively, with TTI improving by $53 \%$. The resulting char for ordinary-sized MH-based WPC increased, but the carbon layer was damaged; hence, it did not act effectively as an insulator for heat and oxygen. Of interest, the ultrafine $\mathrm{MH}$ improved the overall mechanical properties of the WPCs. The amount of WF also plays a critical role in the fire performance of the resulting WPCs with FRs. Elsewhere, there was an increase in WF, while keeping the MH concentration constant (i.e., 10\%), resulted in the reductions of pHRR and THR [29]. The best fire performance was obtained from WF/PP/MH (60/28/10), which exhibited 45 and $25 \%$ reductions for pHRR and THR with TTI increased by $55 \%$ when compared to $\mathrm{WF} / \mathrm{PP}(40 / 58)$ composites. It was also reported that WF/PE/MH 50/35/10 reduced the pHRR and THR by 43 and $30 \%$, meanwhile, TTI increased by $27 \%$ in comparison with WF/PE 50/45 [6]. The pHRR, THR and HRR for the composites, decreased significantly with the addition of ATH and MH [59]. The best reduction in mass loss (ML) (8.43\%) and the total smoke production (TSP) were achieved with the addition of $5 \% \mathrm{MH}$, i.e., HDPE/WF/MA-g-PE/ Lubricant/MH 35.5/50.6/3.6/5.3/5.0. During the decomposition process, $\mathrm{MH}$ degraded into magnesium oxide and water hence absorbed heat from the sample 
and formed a protective layer for the interior material, which acted as a smoke suppressor. In the case of ATH, its low flame-retarding property resulted in the decomposition of the host matrix to produce volatile gases, which promoted the overall destruction of the sample.

\subsection{Phosphorus-based}

Phosphorus-based flame-retardant materials, e.g., ammonium phosphate, diammonium phosphate, and melamine phosphate, have also been reported in the literature due to their environmental-friendliness when compared to their halogenated counterparts $[22,58,60,61]$. The flame retardancy mechanisms of phosphorus-based products are still not easily interpreted, but they involve char formation and vapor phase activity [61]. It is recognized that the amount of phosphorus plays a major role in the flame resistance of phosphorus-based FRs [61]. A large amount of phosphorus content in FR, often results in low FRs loadings [61].

Pan et al. [62] reported that LOI of HDPE/WF/APP (56/30/14) composite increased by $17 \%$, the average HRR and pHRR decreased by 10 and $25 \%$, respectively, and THR by $7 \%$, while the time-to-ignition (TTI) was prolonged by $43 \%$. APP-based WPC had char, which was completely compact with few detectable cracks (with SEM images confirming that the composite exhibited char that consists of decomposed substance from APP homogeneously clustered in the carbon framework). Long-chain APP degrades at temperatures above $300{ }^{\circ} \mathrm{C}$, to generate ammonia and phosphoric acid, whereas the short-chain type decomposes at $150{ }^{\circ} \mathrm{C}$. Of all phosphorus FR products, APP is the most commonly used, followed by diammonium phosphate (DAP), and it is not as effective as APP. Other phosphorus-based FR, include melamine phosphate (MP), which is still not as effective as APP [63]. Red phosphorus (RP), aluminum phosphinate (AP) were also reported in the literature for WPC. The comparison between MP and APP was conducted by Arao et al. [54]. It was reported that $10 \mathrm{wt} \%$ of these FRs are required to produce selfextinguishable properties, but APP performed better as FRs than MP. This was, ascribed to the fact that APP interacts with wood during combustion, thereby forming stable char residue. APP facilitates esterification, dehydration, and char formation of WPC; hence, it enhances the fire performance of the composite products.
It is, however, recognized that a large amount of ammonium phosphate is required in order to realize its flame-retarding efficiency. This results in a higher cost and poor interfacial adhesion in the composite products. A suitable solution has been to combine APP with other nanoscale fillers [62]. The synergistic effect between APP and these nanofillers shows that these particles promote catalyzing reactions between APP and the polymers, therefore, enhancing the thermal stability of the char layer and hence, leading to a compact char structure and improved flame retardancy of the composite materials and it will be discussed in subsequent sections. Nonetheless, APP has been reported as one of the most effective FR for WPCs. However, its water-solubility limits the application for the resulting WPC since they will not be suitable for products exposed to exterior environments. Functionalization of APP was found to improve the flame retardancy of APP-based WPCs. In order to improve the flame retarding property of WF/ PP composites containing $60 \mathrm{wt} \% \mathrm{WFs}$, APP was modified via ion exchange reaction with ethanolamine (ETA-APP) [64]. LOI for the resulting WPC consisted of $30 \mathrm{wt} \%$ ETA-APP was $43 \%$, which corresponds to a $71.6 \%$ increase when compared with that of WPCs containing the same amount of APP, i.e., $30 \mathrm{wt} \%$. The composite showed no dripping with UL-94 rating of V-0 with a significant reduction of pHRR by $40.5 \%$, av-HRR by $49.2 \%$, and THR by $35.8 \%$. Such improvements were, ascribed to the difference in char structures, as shown in Figure 2. The presence of APP alone resulted in continuous char with some holes and flocculent structures because of the cross-linked polyphosphoric acid that was formed during heating, providing a less compact softened glass coating on the surface of the sample, as shown in Figure $2 \mathrm{a}_{1}$ and $2 \mathrm{a}_{2}$. Intumescent char, however, obtained from ETA-APP-based samples, is continuous and more compact with a glass film covering the char layer (see Figure $2 b_{1}$ and $2 b_{2}$ ). Notably, ETAAPP-based samples showed no significant influence on the mechanical properties when compared to the neat WPCs due to the good interfacial adhesion between WF and ETA-APP.

Elsewhere, the efficiencies of diammonium phosphate (DAP) and aluminum diethyl phosphinate (OP) as FRs for WPC (PP/WF 50/50) were investigated [60]. It was reported that WPC $75 \mathrm{wt} \% / 25 \mathrm{wt} \%$ DAP attained a UL-94 V-0 rating. DAP decomposes to ammonia, water and phosphoric acid, which can further 


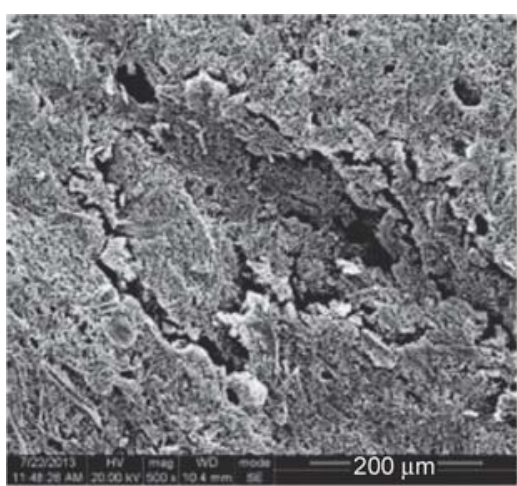

$\left.a_{1}\right)$

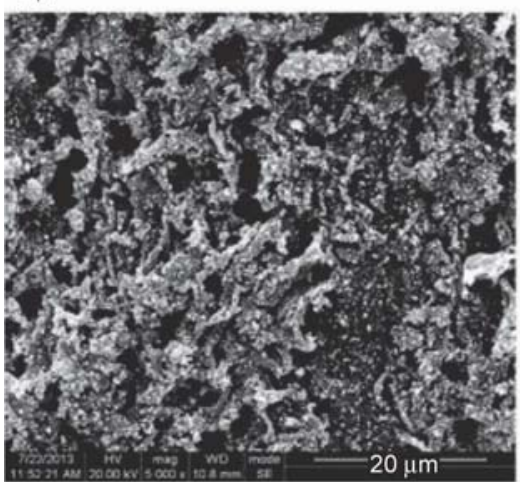

$\left.a_{2}\right)$

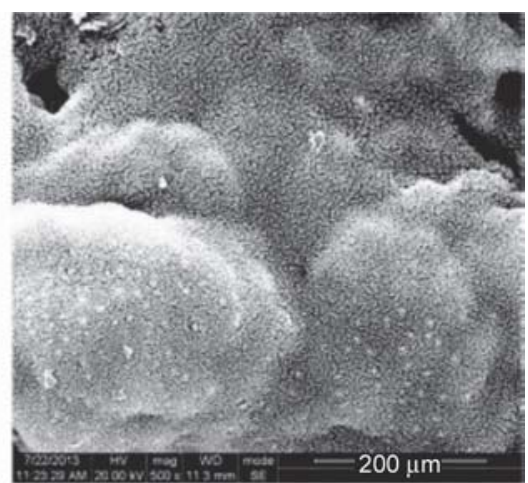

$b_{1}$ )

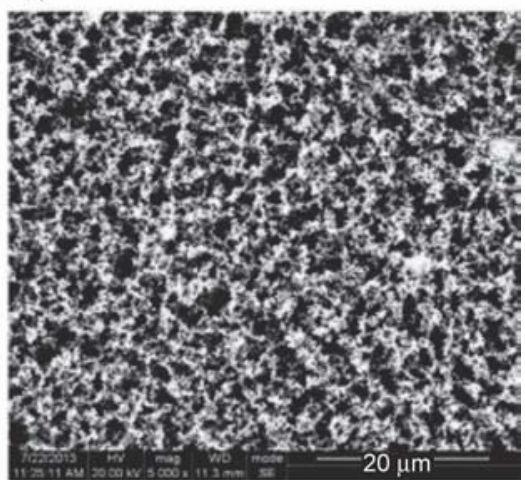

$b_{2}$

Figure 2. SEM images of residual char after cone calorimetry test for $\left(a_{1}\right.$ and $\left.a_{2}\right)$ WPC/30 wt $\%$ APP and $\left(b_{1}\right.$ and $\left.b_{2}\right)$ WPC/ $30 \mathrm{wt} \%$ ETA-APP. Reprinted with permission from [64]. Copyright (2015) American Chemical Society.

dehydrate to produce phosphorus-containing and/or forming $\mathrm{P}_{4} \mathrm{O}_{10}$ (or $\mathrm{P}_{2} \mathrm{O}_{5}$ ) layers, like any other phosphorus-based FRs. The layers formed act as barriers for heat and oxygen transfer, meanwhile releasing $\mathrm{NH}_{3}$ and $\mathrm{H}_{2} \mathrm{O}$ to induce flame inhibition due to the cooling effect and fuel dilution of the oxygen and fuel gases during burning. Besides, OP not even attaining the UL-94 rating V-0, OP also decomposes at higher temperatures, which allows it to act in both phases (i.e., the vapor phase and the condensed phase). In the case of the vapor phase, diethylphosphinic acid is released and vaporized to the gas phase to produce free radicals responsible for capturing $\mathrm{H}^{*}$ and $\mathrm{OH}^{*}$. In the condensed phase, phosphoric acid and/or phosphorus-containing compounds self-condense or combine with other products from WPC combustion to form stable char to protect and impede the transfer of heat and flammable gases between flame zone and interior materials. LOI values for DAP-based and OP-based WPCs were 29 and 28\%, respectively. The increase in DAP (10-40 wt \%) in WF/expanded polystyrene waste (EPS) composite resulted in an increase in the LOI values from 19.5 to $24.3 \%$; meanwhile, the burning rate decreased from $44.6 \mathrm{~mm} / \mathrm{min}$ to $20.1 \mathrm{~mm} / \mathrm{min}$ for only $10 \mathrm{wt} \%$ DAP [65]. In the case of $20-40 \mathrm{wt} \%$ DAP, the flame did not pass the
$25 \mathrm{~mm}$ reference mark. The comparison between triphenyl phosphate (TPP), aluminum hydrogen phosphate (AP), and DAP as FRs for PVC/WFs was investigated by Hoang et al. [61]. The mode of action for these FRs involves their volatilization into gases, acting as fuel dilution and flame inhibition, followed by the formation of a char layer that serves as thermal and oxygen barriers, as shown in Figure 3. A UL-94 rating of V-0 was obtained for WPCs containing $1 \mathrm{wt} \%$ DAP, $1.5 \mathrm{wt} \%$ TPP and $20 \mathrm{wt} \%$ AHP. It was, found that AHP promoted char formation (which acted as a barrier for oxygen and heat transfer during combustion), indicating this type of FR can act via a condensed phase; meanwhile, DAP and TPP act via a gas phase action. TPP volatilized into active radicals, i.e., $\mathrm{PO}_{2}{ }^{\circ}, \mathrm{PO}^{\circ}$, and $\mathrm{HPO}^{\circ}$, which acted as scavengers of $\mathrm{H}^{*}$ and $\mathrm{OH}^{\cdot}$ radicals, hence, suppressed flame during combustion (Figure 3). DAP vaporized into ammonia, water, and phosphoric acid at temperatures of between $160-600^{\circ} \mathrm{C}$. Water and ammonia acted as fuel dilution, whereas phosphoric acid was further dehydrated to pyrophosphoric acid and proceeded to produce $\mathrm{P}_{4} \mathrm{O}_{10}\left(\right.$ or $\left.\mathrm{P}_{2} \mathrm{O}_{5}\right)$ at a slow rate (Figure 3).

Phytic acid, $\mathrm{Ph}$ is a saturated cyclic acid that can be derived from rice bran, beans, and oilseeds; hence, 


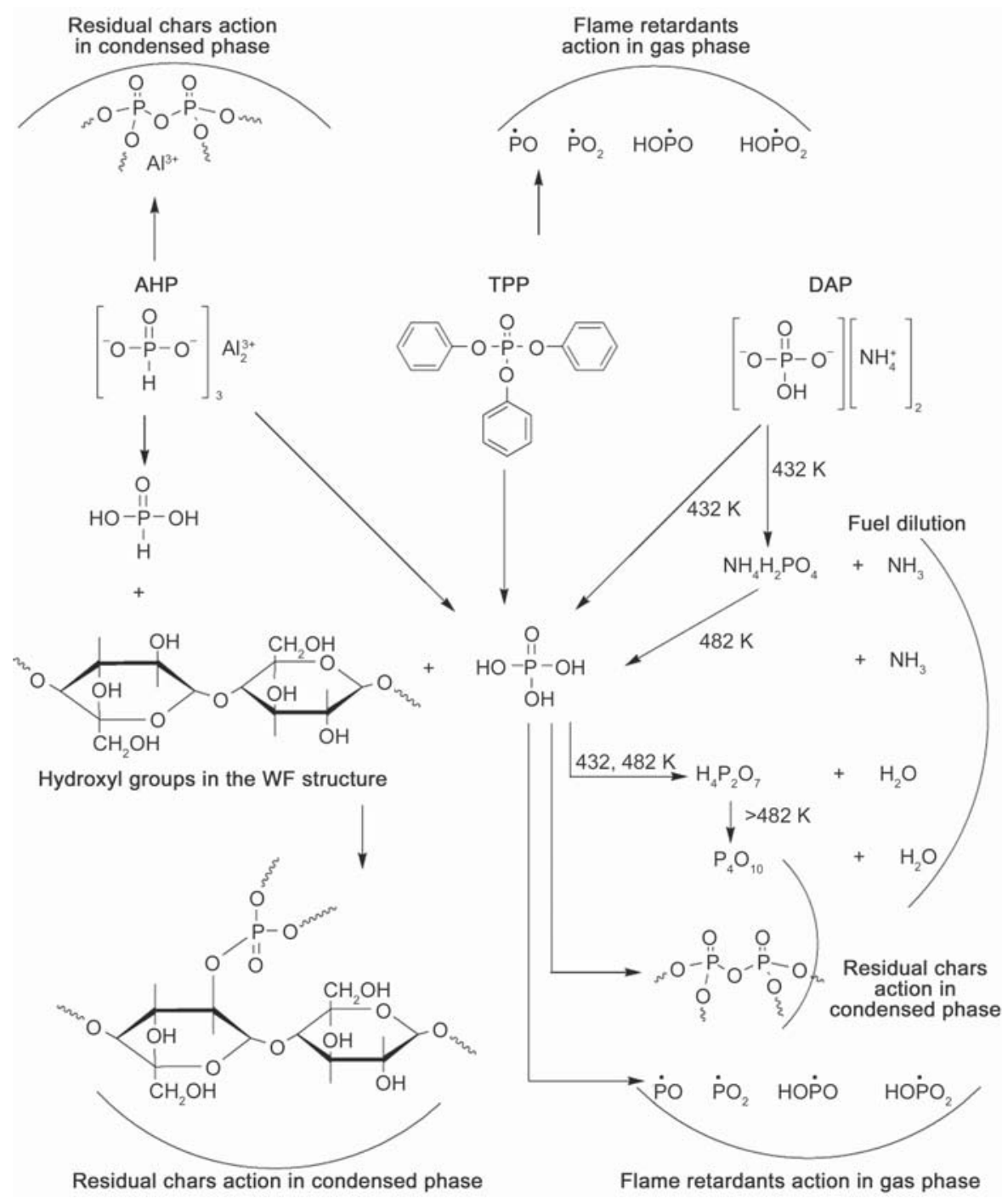

Figure 3. Mechanism for the decomposition of phosphorus-based FRs. During burning phosphorus-based, FRs decompose to different radicals, which act as scavengers for $\mathrm{H}$ and $\mathrm{OH}$ radical or fuel dilution to suppress combustion or facilitate the formation of compact protective char. Reprinted from [61].

it is considered eco-friendly, non-toxic, and cheap [66-68]. It has a high phosphorus content ( $28 \mathrm{wt} \%)$, which makes it a potentially valuable eco-friendly FR. A very recent study, based on the treatment of WFs by immersion in phytic acid $(\mathrm{Ph})$ solution as a novel route to manufacture bio-based FRs-based WPCs, was conducted by Kong et al. [30]. This type of process offers a new opportunity to introduce phosphorus-moieties into WFs without compromising the interfacial interaction between WFs and the host polymers. However, 3-aminopropyltriethoxisilane (KH550) was, used to promote the interfacial adhesion between WFs and $\mathrm{Ph}$ via ionic bonds. It was, found that PLA was flammable with an LOI value of $21.3 \%$ and dripped during combustion and the LOI value slightly increased to $22.1 \%$ with the addition of $15 \%$ untreated WFs. The presence of WFs showed a dripping behavior and ignited at $11 \mathrm{~s}$ and extinguished at $12 \mathrm{~s}$, with the second ignition of the composite dripped from $2 \mathrm{~s}$ and extinguished when reaching $16 \mathrm{~s}$; hence it is rated UL-94 V-2. The addition of Ph-treated WFs, i.e., $5 \mathrm{wt} \%$ and $10 \mathrm{wt} \%$, increased the LOI values to 33.8 and $37.5 \%$, respectively, with both samples attaining the UL-94 V-0 rating. The efficiency of Ph-treated WFs was ascribed to the presence of both $\mathrm{Ph}$ and the coupling agent. $\mathrm{Ph}$, as phosphorus-based FRs, decomposes into phosphoric or polyphosphoric acid, which promotes pyrolysis of WFs into a stable char, needed to protect the underlying composite. Moreover, the phosphorus compounds act as scavengers of free radicals $\mathrm{H}^{\circ}$ and $\mathrm{OH}^{\circ}$, hence hindering the combustion process. The amino groups from the coupling agent result in $\mathrm{NH}_{3}$ and $\mathrm{H}_{2} \mathrm{O}$ during the combustion process to dilute flammable gases or volatiles. 


\subsection{Boron-based FRs}

Boron-based FRs are often employed due to their unique features, such as less toxicity and low cost. Zinc borate is the most commonly used boron-based FR [69]. It has high thermal stability, and it promotes the formation of a glass protection layer in order to prevent further sample destruction during decomposition. It is also known for its smoke suppression efficiency. ZB facilitates the reaction with the $-\mathrm{OH}$ from cellulose and hemicellulose in order to improve char formation in WPCs. Fang and coworkers [70] reported that the presence of $\mathrm{ZB}$ (i.e., $6 \mathrm{wt} \%$ ) in $\mathrm{PVC}$ $(100 \%) / W F(60 \mathrm{phr})$, had no significant influence on the flame retardancy of the composite but a significant decrease in the smoke extinction area (av-SEA) and the total smoke production (TSP) by $\sim 43.36$ and $\sim 50.77 \%$ was observed, indicating the efficiency of $\mathrm{ZB}$ as a smoke suppressant of the composite material. Furthermore, CO production of ZB-containing composite was, reduced by about $\sim 20 \%$ when compared to the composite without $\mathrm{ZB}$. The char residue for the ZB-containing samples increased by $\sim 56.2 \%$ when compared to the PVC/WF composite. This was, ascribed to the ZB ability for early crosslinking of PVC with zinc chloride during decomposition. This was as a result of the thermal decomposition of PVC, therefore, acting as an effective catalyst for the dehydration and charring of WFs. Raw boron minerals, i.e., tincalcinite $\left(\mathrm{Na}_{2} \mathrm{~B}_{4} \mathrm{O}_{7} \cdot 5 \mathrm{H}_{2} \mathrm{O}\right.$, boron content of $15.16 \%)$, colemanite $\left(\mathrm{Ca}_{2} \mathrm{~B}_{6} \mathrm{O}_{11} \cdot 5 \mathrm{H}_{2} \mathrm{O}\right.$, boron content of $15.78 \%$ ), and ulexite $\left(\mathrm{NaCaB}_{5} \mathrm{O}_{9} \cdot 8 \mathrm{H}_{2} \mathrm{O}\right.$, boron content of $13.34 \%$ ), were tested as suitable FRs. These tests were compared to the commonly used $\mathrm{MH}$ and $\mathrm{ZB}\left(2 \mathrm{ZnO} \cdot 3 \mathrm{~B}_{2} \mathrm{O}_{3} \cdot 3.5 \mathrm{H}_{2} \mathrm{O}\right.$, boron content of $\left.14.92 \%\right)$ as well as borax $\left(\mathrm{Na}_{2} \mathrm{~B}_{4} \mathrm{O}_{7} \cdot 10 \mathrm{H}_{2} \mathrm{O}\right.$, boron content of $11.34 \%$ ) [69]. It was, found that pHRR and aveHRR were, reduced with the addition of all the investigated FRs, and in addition, the TTI was prolonged than that of the neat WPC. The highest TTI was obtained from $\mathrm{MH}$ (i.e., $42.2 \mathrm{~s}$ ) and ulexite (i.e., $36.6 \mathrm{~s}$ )-based WPCs at $15 \%$ loading. MH- and colemanite-based WPCs exhibited the highest $\mathrm{pHRR}$ reduction of $\sim 42$ and $\sim 40 \%$, respectively, in comparison with the neat WPCs. Ulexite-, tincalconite-, borax- and ZB-containing WPCs had their pHRRs decreased by $\sim 38$, $\sim 36, \sim 33$ and $\sim 34 \%$, respectively. The aveHRR, fire growth index (FGI), average effective heat of combustion (AEHOC), and average specific extinction area (ASEA) reductions for all the investigated samples, indicated the fact that these boron-based minerals can be, used as alternative FRs for WPCs. However, colemanite-based WPCs exhibited the best flame retardancy performance without losing their flexural properties. This was attributed to a large amount of boron and its high thermal stability characteristics, and hence, it is considered as potentially cheaper (with MH being two times more expensive with similar properties) and environmentally friendly FR.

\subsection{Carbon-based materials}

Expandable graphite (EG) is the most promising FR; however, it has its expansion result in char with cracks, which in turn exposes the interior materials and hence, compromising the overall flame retardancy property of the resulting WPCs $[28,34,71]$. During the burning process, the WPCs containing EG, formed char layers (as depicted from the HHR curve of the first peak), which followed the second peak related to the breakage of the char due to the expansion of EG. This results in the loosely bound residue, thereby allowing pyrolysis gases to pass through and again, does not provide any form of protection to the interior materials. Nonetheless, Seefeldt et al. [71] found that EG exhibited a pHRR reduction of $\sim 73 \%$ when compared to the neat WPCs due to its good thermal barrier properties. Hence, the combination of EG with other FRs, which can reinforce char, results in effective flame-retarding materials. The inexpensiveness and the non-toxicity of EG, with its extensive sources and simple preparation, make it the most interesting FR material; hence it has been widely employed in flame-retardant polymeric materials, especially the WPCs $[2,28,42,72,73]$. The limitations, such as the lack of interfacial adhesion, poor dispersion, and the expansion experienced during burning, makes it difficult to be used alone as FR material; hence, it is often combined with other FRs as well as its surface modification [28, 74]. Epoxy resin/WF/EG was found to be a more flame-resistance material without the need of additional compound and/or filler [42]. It was, found that EG expanded under fire and formed a worm-like structure, which hindered fire progression by limiting the mass and gas transfer from the WPC to the heat source, hence protecting the underlying material. Even when the EG/epoxy resin mixture was used as a coating layer for WPC, the total flame time (TFT) and drip flame time (DFT) were obtained for the samples coated with EG $5 \mathrm{wt} \%$, met Aviation Regulation 
(FAR) requirement. Samples exhibited self-extinguishable flames due to EG expanding during burning. A similar coating strategy was applied in order to establish the effect of expandable graphite on the flammability of the WPCs [75]. EG-based WPC performed better than APP and MH-based composites. It was reported that the EG-based composites exhibited better fire resistance properties for a single layerand multilayer-coated samples (with greater effect were obtained for the multilayer samples) due to the ability of EG to act as a barrier that protects the underlying material from degradation and char formation. Khalil and coworkers from Selangor, prepared for the first time WPCs from WF (20 wt \%)/expandable graphite (EG) $(3,5$ and $7 \mathrm{wt} \%)$ /epoxy resin by using compression molding ( $17 \mathrm{kPa}$ ) for 24 hours [42]. They reported that an increase in the EG content improved the flame retardancy and the thermal properties of the WPC, however, at the expense of mechanical properties. The authors also coated the WPCs with an epoxy resin containing EG (i.e., 3 and $5 \mathrm{wt} \%$ ) and found that content of $5 \mathrm{wt} \% \mathrm{EG}$, was sufficient to provide self-extinguishing properties due to the EG expansion.

Carbon black (CB) anti-flammable properties result from the radical scavenging efficiency and facilitation of char formation during decomposition [76, 77]. Turku et al. [5] reported that with the addition of $3 \% \mathrm{CB}$ into polymer blend (i.e., $40 \%$ composed of LDPE/PP with $69 \mathrm{wt} \%$ of LDPE) consisted of $54 \mathrm{wt} \%$ WF, 3\% coupling agent and 3\% lubricant total heat release (THR) decreased from 141 to $135 \mathrm{~mJ} / \mathrm{m}^{2}$ and the specific mass loss rate (MLR) decreased from 8.0 to $4.6 \mathrm{~g} /\left(\mathrm{s} \cdot \mathrm{m}^{2}\right)$ due to the $\mathrm{CB}$-facilitating char formation, which acted as an insulating barrier. This layer hindered the oxygen transfer process, as confirmed by an increase in $\mathrm{CO}$ production (i.e., from 0.037 to $0.063 \mathrm{~kg} / \mathrm{kg}$ ), correlating with the incomplete burning of the material. Zhou and Kärki [77] fabricated a WPC (consisted of percentage ratios WF:PP: Ma-g-PP:lubricant:pigment:CB 47:43:3:3:1:3) with a continuous and honeycomb-like $\mathrm{CB}$ network ( $\mathrm{WPC}_{\mathrm{H}-\mathrm{CCB}}$ ) by mixing WPC pellets with $\mathrm{CB}$, followed by melt pressing and the uniformly-distributed WPC $\left(\mathrm{WPC}_{\mathrm{U}-\mathrm{CCB}}\right)$, which was obtained by mixing all the additives, followed by extrusion and then melt-pressing. The $\mathrm{WPC}_{\mathrm{H}-\mathrm{CCB}}$ containing $3 \% \mathrm{CB}$, exhibited a decrease and a delay in the second HRR peak as well as the reduction in the THR when compared to the neat WPC. This was, explained to be the result of the efficiency of CB coating WPC, thereby hindering the transmissions of heat and oxygen from penetrating the sample. However, a uniformly distributed CB, displayed minor HRR and THR. SPR and TSP were significantly reduced for the $\mathrm{WPC}_{\mathrm{H}-\mathrm{CCB}}$ with higher mass retention than the control WPC, indicating the excellent fire performance associated with the WPC products towards various building applications (antistatic floor, electromagnetic and flameretardant walls).

CNTs have also been considered as a potential FR for WPCs. The mode of action relies on the formation of a protective network-structured layer needed to prevent heat and flammable gases transfer in or out of the system. The flame resistance performance of the CNT-based composites is dependent on the nanotubes' content and the aspect ratio, as well as the degree of dispersion and the interfacial interaction, like any other nanofiller $[41,78,79]$. With the addition of CNT to WPC, it was found that pHRR was decreased by $\sim 17 \%$, THR by $\sim 7 \%$, and MLR by $\sim 9 \%$ [78]. This is due to the ability of the CNTs to form a network within the host matrix, thereby improving the barrier properties. CNT network could reinforce char and prevent its cracking during combustion, which in turn serves as a good insulator to hinder heat and volatiles transfer in the composite.

Carbon fibers (CFs) were found to reduce pHRR by $\sim 11 \%$, and the effective heat of combustion (EHOC) slightly decreased from 27 to $26.2 \mathrm{MJ} / \mathrm{kg}$ [78]. However, MLR and THR were not changed with the CO production increasing from 0.036 to $0.046 \mathrm{~kg} / \mathrm{kg}$. The reduction of HRR without significant change in THR is often associated with a physical barrier that delays the burning rate without decreasing the overall amount of combustible material. Testing the WPC/CF sample according to ISO 13823 for simulating the Single Burning item, which is often used for building materials, showed that the fire growth rate index (FIGRA) decreased from 802 to $645 \mathrm{~W} / \mathrm{s}$, i.e., from $\mathrm{E}$ class to $\mathrm{D}$ class.

\subsection{Other materials}

Talc $\left(\mathrm{Mg}_{3} \mathrm{Si}_{4} \mathrm{O}_{10}(\mathrm{OH})_{2}\right)$ is one of the commonly used mineral fillers to reinforce polymer composites. Huang et al. [80] studied the effect of talc on the flame retardancy of HDPE/WF composite. LOI values of the WPCs were, found to increase with increasing talc contents, while PHRR was, found to decrease. THR values were also reduced from $302.47 \mathrm{MJ} / \mathrm{m}^{2}$ for a 
$5 \mathrm{wt} \%$ talc content to $262.14 \mathrm{MJ} / \mathrm{m}^{2}$ for a $50 \mathrm{wt} \%$ talc content. This was, attributed to the formation of a continuous surface char layer, which blocked the penetration of fire.

Green FRs are of interest, considering their distinctive properties that include: abundance, rich reactive functional groups, sustainability, and inexpensiveness [46, 48, 51, 81, 82]. Liu and coworkers fabricated bio-based material from industrial lignin, chemically grafted with phosphorus, nitrogen, and copper ions [81]. With $15 \%$ replacement of WFs with the functionalized lignin (F-lignin) (i.e., PP/WF/MA-g-PP/Flignin $76.5 / 5 / 3.5 / 15)$ resulted in $\mathrm{V}-1$ rating from the UL-94 test. From the cone calorimetry tests, it was found that $\mathrm{pHRR}$ decreased by $\sim 21 \%$, THR by $\sim 25 \%$, and TSR by $\sim 27 \%$ when compared to the neat WPC (PP/WF/MA- $g$-PP 76.5/20/3.5), while the TTI increased by $\sim 33 \%$. This was attributed to the presence of a phosphorus-containing moiety in the F-lignin, decomposing to form phosphoric acid, pyrophosphoric, or polyphosphoric acid species, which promoted lignin and WP (especially cellulose, hemicellulose, and lignin) to generate carbonaceous substances via the dehydration process. Meanwhile, the presence $\mathrm{Cu}^{2+}$ ions catalyzes the dehydrogenation carbonization reaction of WPC and lignin. As expected, the presence of the carbonaceous layer prevents the transfer of heat and the diffusion of the combustible products from the decomposition of polymers as well as isolating the oxygen gas, thereby reducing the HRR value, slowing down the combustion process, thereby protecting the underneath materials. Lignin-based flame retardant (LMD) was synthesized by grafting phosphorus elements onto lignin by reacting lignin with 9,10-dihydro-9-oxa-10-phosphaphenanthrene10-oxide (DOPO) and 4,4'-diphenylmethane diissocyanate (MDI) [51]. It was, found that the presence of LMD (15\% of lignin) resulted in an increase in the LOI value from $22.3 \%$ to $25.9 \%$, which further increased to $28.6 \%$ when the coupling agent, triglycidyl isocyanurate (TGIC) was, introduced into the system. LMD-containing WPC with TGIC 4\% exhibited a rating of $\mathrm{V}-0$ under UL-94 and showed no dripping. These results were attributed to the synergistic effect between LMD and TGIC. LMD decomposition results in the formation of $\mathrm{PO}$ from phosphaphenanthrene group free radicals, which can prevent the chain reaction of the active free radical $(\mathrm{OH}$ and $\mathrm{H})$ in the gas phase, thereby promoting char formation. Meanwhile, TGIC decomposes into nitrogenous inert

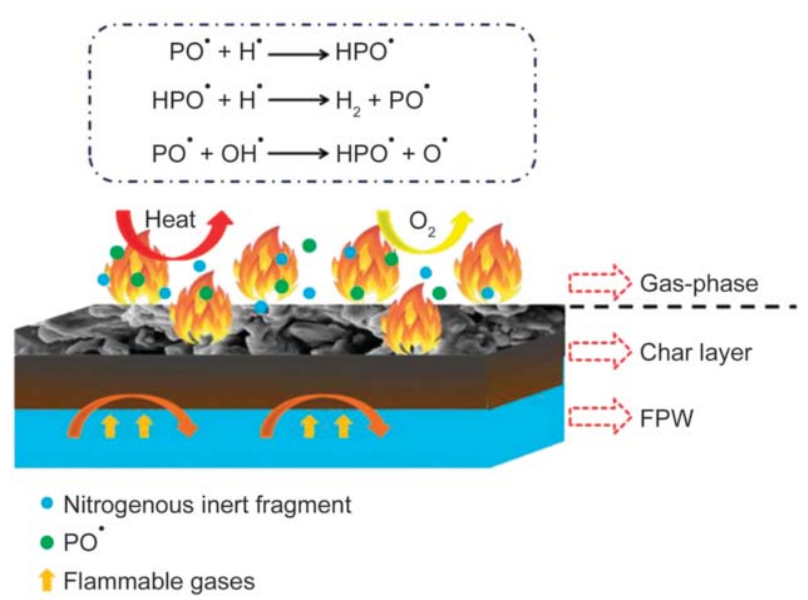

Figure 4. Schematic presentation for flame retardant mechanism of WPC containing functionalized lignin. Reprinted from [51].

fragments, which are of significant importance for flame retarding in the gaseous phase. LMD decomposes in the early stages, which facilitates the decomposition of the matrix and wood from continuous and compact carbon layers responsible for the prevention of heat and oxygen transfer in or out of the sample, as shown in Figure 4.

\subsection{Nanomaterials}

\subsubsection{Organoclays}

The flame retardancy of organoclay-based materials relies on the formation of a carbonaceous layer that protects the underneath material during combustion [83-86]. Clays are layered silicates with surface properties that depend on the nanosheet charge, the nature of surface atoms, and the interlayer exchangeable cations [85]. Clay reinforced polymeric materials were found to decrease the flammability properties of the resulting nanocomposite products. Guo et al. [86] reported that exfoliated clay nano-platelets led to better flame retarding properties for HDPE/WPC that was prepared by using a twin-screw co-rotating extruder. They also found that with an increase in the clay content, the flame retardancy was, enhanced. This behavior was attributed to the formation of the carbonaceous-silicate char, which builds-up on the surface during burning, hence insulating the underlying materials and slowing the mass loss rate of decomposition. A comparison between the degree of clay dispersion, i.e., exfoliated and intercalated structures, were reported by Lee et al. [87]. The presence of clay decreased the burning rate of the composites, but a significant decrease was observed for the exfoliated clay-filled composites, which indicated the 
fact that the exfoliation of clay particles was key to enhancing the flame-retarding efficacy of the WPC. Interestingly, the exfoliated clay-filled WPC usually results in improved mechanical properties. It is, however, reported that the presence of a compatibilizer could improve the overall flame retardancy of the WPC due to the associated increase in melt viscosity, which often increases with an increase in the compatibilizer's content. In general, the flame retardancy of clay-filled WPC relies on the formation of carbonaceous-silicate char on the surface during burning, which in turn insulates the underlying materials and hence, slows down the mass loss and energy release rate of the decomposition products.

\subsubsection{Other nanofillers}

Nano-sized fillers, with their unique features, such as high aspect ratio and large surface area, can improve the flame retardancy performance of a material/composite containing such fillers $[87,88]$. This is due to strong interfacial adhesion between these fillers and WPCs [88]. A strong interfacial adhesion promotes the catalytic behavior of nanofillers, hence facilitating the dehydration and charring of the WPC product. Recently, Zhou et al. [41] conducted a study based on the comparison between micro-silica $\left(\mathrm{SiO}_{2}\right)$ and nano- $\mathrm{SiO}_{2}$ that were incorporated into HDPE/ WFs by using the dry blending (dry dispersion) and solution blending (wet dispersion) techniques. The pHRR of WPCs, filled with $9 \%$ micro-SiO ${ }_{2}$ via dry and wet dispersions was, reduced by $\sim 14.7$ and $\sim 17.1 \%$, respectively; meanwhile, THR decreased by $\sim 14.2$ and $\sim 16.3 \%$, respectively. On the other hand, nano- $\mathrm{SiO}_{2}$-loaded WPC from wet and dry dispersion techniques resulted in pHRR decreasing by $\sim 30.7$ and $\sim 26.4 \%$, respectively, due to the shielding and the catalytic carbonization of nano- $\mathrm{SiO}_{2}$.

Cellulose nanocrystals (CNCs)-APP anionic polyelectrolyte hybrid was prepared by mixing APP with CNCs in order to fabricate non-flammable WPCs with good mechanical properties [89]. Neat WPC had LOI value of $20.1 \%$, indicating that it is highly flammable; however, the inclusion of APP in the system increased the value to $25.9 \%$. LOI values further increased to between $26.3-27.1 \%$ with increases in the APP-CNC loadings from between 1-9 wt $\%$, demonstrating an improvement in the flame retarding property of the resulting composites. The pHRR, aveHRR, and THR values were further decreased for the APP-CNC-based WPCs when these properties were, compared to composites with APP inclusion. The MLR values reduced from 63.8 to $35.8 \mathrm{mg} / \mathrm{s}$ for the APP-based WPCs and further reduced to 30.4$32.3 \mathrm{mg} / \mathrm{s}$ for the APP-CNC-based WPCs. The flame retarding efficiency of CNC-APP is believed to be the result of the enhanced thermal stability of the carbon layers, hence, effectively reducing the heat released during burning.

\subsection{Synergistic systems}

In most cases, the inclusion of one FR into the WPCs, may not be sufficient to enhance the nonflammability property; thus, an additional inclusion of FR often, if introduced into the system, is known as synergist [50]. The presence of a synergist can also improve the overall physical and mechanical properties while reducing the amount of FR required to achieve the desired flame retardancy property.

\subsubsection{Metal hydroxide and others}

Aluminum hydroxide and APP were introduced into a WF/PP composite at different APP to ATH mass ratios and at a constant loading of $30 \mathrm{wt} \%$ [90]. From a cone calorimetry test, it was, deduced that WPC containing APP 20\% and ATH 10\% performed better than other samples. The TTI was, prolonged from 15 to $29 \mathrm{~s}$ (almost double), and pHRR, HRR, and THR values were, decreased from 1003 to $498 \mathrm{~kW} / \mathrm{m}^{2}$, 292 to $164 \mathrm{~kW} / \mathrm{m}^{2}$, and 170 to $115 \mathrm{MJ} / \mathrm{m}^{2}$, respectively. Char residue increased from $6 \%$ to $\sim 22 \%$ due to the ability of aluminum hydroxide to react with APP in order to generate a thermally stable aluminumorthophosphate and aluminum-metaphosphate needed to protect the underlying matrix.

\subsubsection{Phosphorus-based and others}

Nanofillers are preferably employed as the second filler in WPC due to the relatively small amounts that are often required to realize their impact on the flame resistance efficiency [28, 40, 49, 91]. A combination of hypophosphorus acid-based ionic (BMP) liquid and $\mathrm{EG}$ at a 2:1 ratio (30 $\mathrm{wt} \%$ ) resulted in an LOI value of $31.5 \%$, and the sample passed the UL-94 (i.e., $\mathrm{V}-0$ rating) [28]. The composite displayed a reduction in pHRR by $65 \%$ when compared to the pure WPC and had its TTI increased by $15 \mathrm{~s}$. The composite also displayed the lowest total heat release (THR), the maximum average rate of heat emission (MARHE, a measure of the propensity for fire development). This value decreased from 288.28 to 
$98.35 \mathrm{~kW} / \mathrm{m}^{2}$, the total smoke production (TSP) decreased by $66.6 \%$ and had the highest fire performance index (FPI) value $\left(0.28 \mathrm{~s} \cdot \mathrm{m}^{2} / \mathrm{kW}\right)$ and the lowest fire growth index (FGI) of $0.76 \mathrm{~kW} /\left(\mathrm{s} \cdot \mathrm{m}^{2}\right)$. This synergy emanated from the catalyzing efficiency of BMP, necessary for the promotion of char formation and the physical barrier formed by EG. Furthermore, the addition of these nanoparticles is often associated with decreases in the amounts of the other fillers, while even better overall properties can be obtained. Pan et al. [62] found that the introduction of nanosilicon dioxide (nano- $\mathrm{SiO}_{2}$ ) into a WPC/APP system led to enhanced flame retardancy. A hybrid APP $8 \% /$ nano $\mathrm{SiO}_{2} 6 \%$ inclusion resulted in the reductions of the average and peak HRRs by 42 and $44 \%$, respectively, whereas TTI increased by $78 \%$ due to the excellent interaction between the wood fiber, APP, and nano- $\mathrm{SiO}_{2}$, which promoted early thermal degradation of WPC and stabilized the resulting char residue. Furthermore, the presence of the nano- $\mathrm{SiO}_{2}$ formed an intercalated network within the char structure, enhancing its physical integrity and hence, resulting in an effective synergistic effect on the flame retardant (MP and aluminum phosphinate (AP), in flame-retardant behaviors of HDPE/wood flour composite, with PE-g-MAH as compatibilizer. Liang et al. [40], prepared a WPC containing both APP and Fe particles by using the solution casting technique. They found that the higher APP content, the higher the LOI values, and the samples displayed the V-0 rating without dripping. Cone calorimetry results demonstrated the fact that HRR, THR, and TSP of the WPCs containing both Fe and APP were significantly decreased when compared with samples without APP. This was, ascribed to the activity of APP, which promoted the decomposition of WF into the carbon layer, which prevented combustion and protected the WPCs from further destruction. The MP/AP ratio was kept at 3:2. An LOI value of $29.6 \%$ was achieved, viz., $\mathrm{V}-0$ rating at $35 \mathrm{wt} \%$ of MP/AP. This was, attributed to the MP/AP being able to produce an intumescent char layer, which protected the material from burning. It was reported that the flame retardancy was significantly improved with the HRR and THR values reduced from $422 \mathrm{~kW} / \mathrm{m}^{2}$ and $103 \mathrm{MJ} / \mathrm{m}^{2}$ to $166 \mathrm{~kW} / \mathrm{m}^{2}$ and $43 \mathrm{MJ} / \mathrm{m}^{2}$, respectively. Meanwhile, the TTI and char residue values increased from $35 \mathrm{~s}$ and $15.7 \%$ to $43 \mathrm{~s}$ and $60.1 \%$. This phenomenon was ascribed to the excellent synergy that existed between the FRs. The mechanism proposed was that in a condensed phase, MP and AP played different roles, with AP decomposing into phosphoric acid and promoting char layer formation, while MP was decomposing at higher temperatures to produce phosphate, which promotes wood flour dehydration and catalyzes esterification, and further accelerates the thermal degradation of WPC in order to generate extremely compact char layer structure. The char layer acts as a barrier to protect the interior material, whereas the generated incombustible gas, such as $\mathrm{NH}_{3}$ and $\mathrm{H}_{2} \mathrm{O}$, dilute the fuel gases and hence, improving the flame retardancy of the WPC.

The combination of expandable graphite (EG) and APP as well as the double-layered APP and EGbased WPCs, were also reported in the literature [92]. It was found that the synergistic effect between APP and EG, reduced the pHRR, TTI values, and smoke released because EG and APP catalyzed the WF into char during burning. The char layer formed, protected the interior materials, thereby improving the flame resistance properties of the WPC. In the case of double-layered composites, the cap layer with EG and APP in the base was found to be very effective for fire protection. This was attributed to the formation of intumescent structured char by EG, which effectively protected the base layer from thermal decomposition and absorption of the volatiles from the base. On the contrary, the cap layer of the APP, formed a discrete char layer, which could not effectively protect the interior materials from combustion and further cracked due to the expansion of the base; hence the volatiles easily escaped from the system. The combination of APP/EG, red phosphorus (RP)/EG, and RP/APP was also reported by Seefeldt et al. [71]. It was found that APP and RP exhibited a gas-phase and condensed phase mechanisms, with the resulting residue increasing by $\sim 25 \%$ when compared to WPC without FRs. It was, reported that the solid phase action of APP, in combination with RP, increased when compared to WPC/APP, and the gas phase action of $\mathrm{RP}$ in combination with APP was slightly improved when compared to WPC/RP. RP/EG also showed a gas-phase and condensed phase mechanisms, with the residue being higher when compared to WPC/EG and WPC/APP. This is due to the synergistic effect between RP and EG, resulting in increased storage of phosphorus in the condensed phase. It was, found that the presence of RP and APP cross-linked the char and prevented its disruption, thereby resulting in the best fire performance, according to the cone 
calorimeter tests. In the case of APP and RP, there was no significant improvement in fire performance when compared to samples with single flame-retardants. Glycerin-decorated APP (APD-APP) displayed a good fire resistance performance when compared to the WPC-containing APP alone [35]. The LOI for $30 \mathrm{wt} \%$ APD-APP/WPC increased to $36 \%$, which is $\sim 44 \%$ higher than that of WPC/APP. The combustion of WPC was more intense, with the observed fire spread being beyond $5 \mathrm{~cm}$ in less than $200 \mathrm{~s}$. Meanwhile, WPC/25\%APP burnt slower, and the combustion was maintained for a long time without self-extinguish within $200 \mathrm{~s}$. On the other hand, the decomposition of $\mathrm{WPC} / 25 \%$, the APD-APP burning was slower and mild, and it was self-extinguish at $\sim 120 \mathrm{~s}$. The pHRR values were found to decrease by 40.4 , 62.3 , and $70.0 \%$ for the 20,25 , and $30 \mathrm{wt} \%$ loadings of APD-APP, respectively when compared to the neat WPC.

\subsubsection{Boron-based and others}

Boron-based flame retardants are known to facilitate char formation and suppress the release of smoke during burning without releasing toxic products. In order to improve the flame retardancy performances of zinc borate with APP, dipentaerythritol (DPER) and melamine (MEL) composite were studied by Ren et al. [93]. The LOI values increased from 18.1 to $37.7 \%$, and the UL-94 rating of V-0 was obtained. Prolonged TTI and a reduction in pHRR by $70 \%$, avHRR by $63.8 \%$, MLR by $62.6 \%$, and TSR by $75 \%$ indicate a positive synergic effect between all the incorporated additives. A synergistic system composed of boron-based (boric acid (BA, $\mathrm{H}_{3} \mathrm{BO}_{3}$ ) and borax $\left(\mathrm{BX}, \mathrm{Na}_{2} \mathrm{~B}_{4} \mathrm{O}_{7} \cdot 10 \mathrm{H}_{2} \mathrm{O}\right)$ materials) was recently reported [32]. In this case, WFs were immersed in the mixture of $5 \%$ of BA and $\mathrm{BX}(50: 50 \mathrm{w} / \mathrm{w})$ and then introduced into HDPE/wax melt by using the twinscrew extruder, followed by injection molding. From the vertical burning tests, according to ASTM D 635 , the burning rate of the samples was decreased from 37.20 to $17.25 \mathrm{~mm} / \mathrm{min}$ with the addition of $40 \mathrm{wt} \%$ of the BX/BA treated WFs. This is due to the formation of a coating layer from WFs and polymer decomposition. Consequently, there was a reduction in the rate of heat conduction into the underneath composite, hence decelerating the decomposition rate of the host polymer.

\subsubsection{Organoclays and others}

The combination of three different FRs was also reported to have improved the LOI of WPC from 19.51 to 24.5 vo\% [7]. Deka and Maji [38] reported a balanced WPC system reinforced with 3\% clay $/ 3 \%$ titanium oxide $\left(\mathrm{TiO}_{2}\right)$. This composite exhibited superior mechanical properties and had a high LOI of $67 \%$. This was, attributed to the nanoclay producing silicate char on the surface of WPC, which provided a tortuous path for oxygen and heat, which delayed the decomposition of the composite. Meanwhile, $\mathrm{TiO}_{2}$ provided a thermal barrier to oxygen and heat, resulting in an improvement in flame retardancy. Montmorillonite (MMT) combined with APP, dipentaerythritol (DPER), and melamine (MEL) was added to a $\mathrm{PP} / \mathrm{WF}$ composite to enhance flame-retarding property [93]. Besides MTT contributing towards the improvement of tensile strength, flexural modulus and Izod impact and the flame resistance properties were enhanced. With the addition of 5\% MTT to APP, dipentaerythritol (DPER), and melamine (MEL) system, WPC changed from flammable material (LOI value of $18.1 \%$ and UL-94 rating failed) to nonflammable material (LOI value of $35.3 \%$ and UL-94 rating of V-0). From cone calorimetry tests, it was deduced that TTI was prolonged from 37 to $130 \mathrm{~s}$, meanwhile, pHRR decreased by $66.3 \%$, avHRR by $63.8 \%$, and MLR by $52.3 \%$. Moreover, the EHC dropped from 31.57 to $23.87 \mathrm{MJ} / \mathrm{kg}$, clearly indicating the fact that the material is the best candidate as far as combustion safety is concerned.

\subsubsection{Carbon-based}

In order to overcome the limitations of EG, several FRs were combined with EG to manufacture a synergist system [34]. Guo et al. [72] studied the synergistic effect of EG and APP in WPC with 3-(methylacryloxyl) propyltrimethoxysilane ( $\mathrm{KH}-570)$, as a coupling agent. It was found that the addition of both EG and APP resulted in good flame retardancy as all the samples passed UL-94 vertical tests and the LOI value increased with the EG content. A ratio of 1:1 APP/EG was the optimal content to attain the maximum synergistic effect with a maximum LOI value of 39. This composite exhibited a long burning time, lower HRR, THR, TSP, and a mass loss value due to the formation of a carbonaceous layer that acted as an insulator and prevented the progression of fire 
along the sample. The residue was composed of continuous worm-like connected expanded graphite flakes and carbonaceous layer, indicating that APP and EG formed a network structure of carbon layer that is capable of prohibiting oxygen into the sample, hence improving the flame resistance performance. The mechanical properties were adversely affected by the addition of EG alone, however, the inclusion of APP, balanced the overall mechanical properties. Zheng and coworkers reported that the highest LOI value obtained was $32.2 \%$ and the $\mathrm{V}-0$ rating at a ratio of EG/APP 12.5:7.5 (20 wt\% overall) [73]. pHRR, HRR, and TSR were drastically decreased for the EG/APP-containing WPC when compared to the WPC without FRs, and the burning time and residue [\%] were increased. Loosened worm-like char residue structure covered with the granular substance of viscous phosphoric acid or poly(phosphoric acid) from APP decomposition resulted in a more effective fire retardancy. The effect of EG and APP on the flame resistance of WPC containing carbon black (CB) was

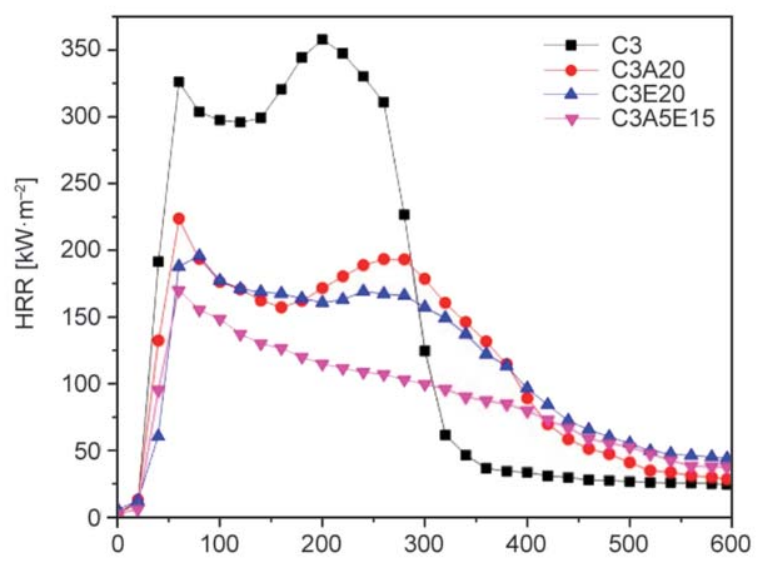

a)

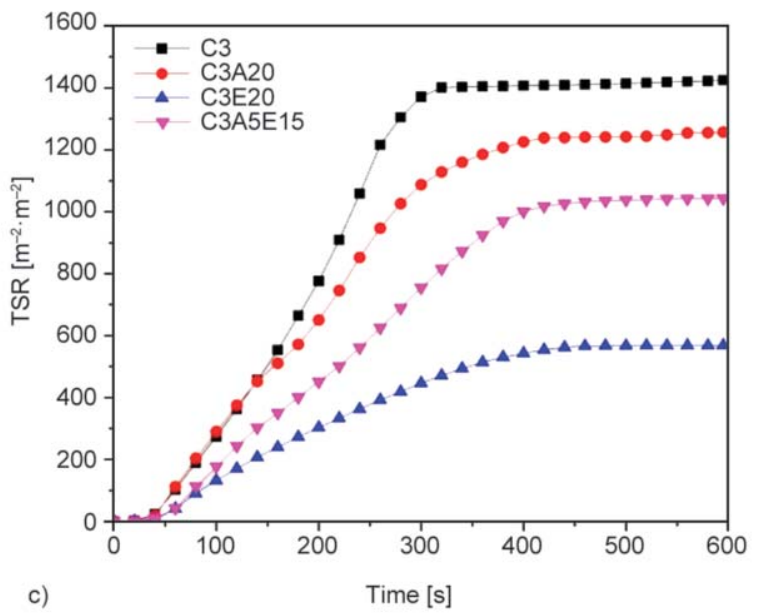

investigated by Yu et al. [76]. When compared to the WPC containing $\mathrm{CB}$, the HRR peaks were, found to decrease significantly with pHRR for C3E20, decreasing by $\sim 49.8 \%$, C3A5E15 by $\sim 52.7 \%$, and C3A 20 by $\sim 2 \%$ (Figure $5 \mathrm{a}$ ). It was reported that the burning times were also prolonged when compared to the $\mathrm{C} 3$ because of the decomposition of the transient char. THR for APP and EG containing WPC was similar with a significant reduction exhibited by C3A5E15 (Figure 5b). Meanwhile, the EG-containing samples showed significant decreases in TSR (Figure 5c). The residual mass, which is associated with char formation efficiency, increased by $\sim 38.8 \%$ for C3A5EG15 (see Figure 5d), indicating that the combination of $\mathrm{EG} / \mathrm{CB} / \mathrm{APP}$ resulted in efficient fire retardancy.

\subsubsection{Other materials}

Ren et al. [93] studied the influence of the incorporation of 5\% nanofillers (stannic oxide (TD) and manganese oxide (MD)) into a recycled PP/WF
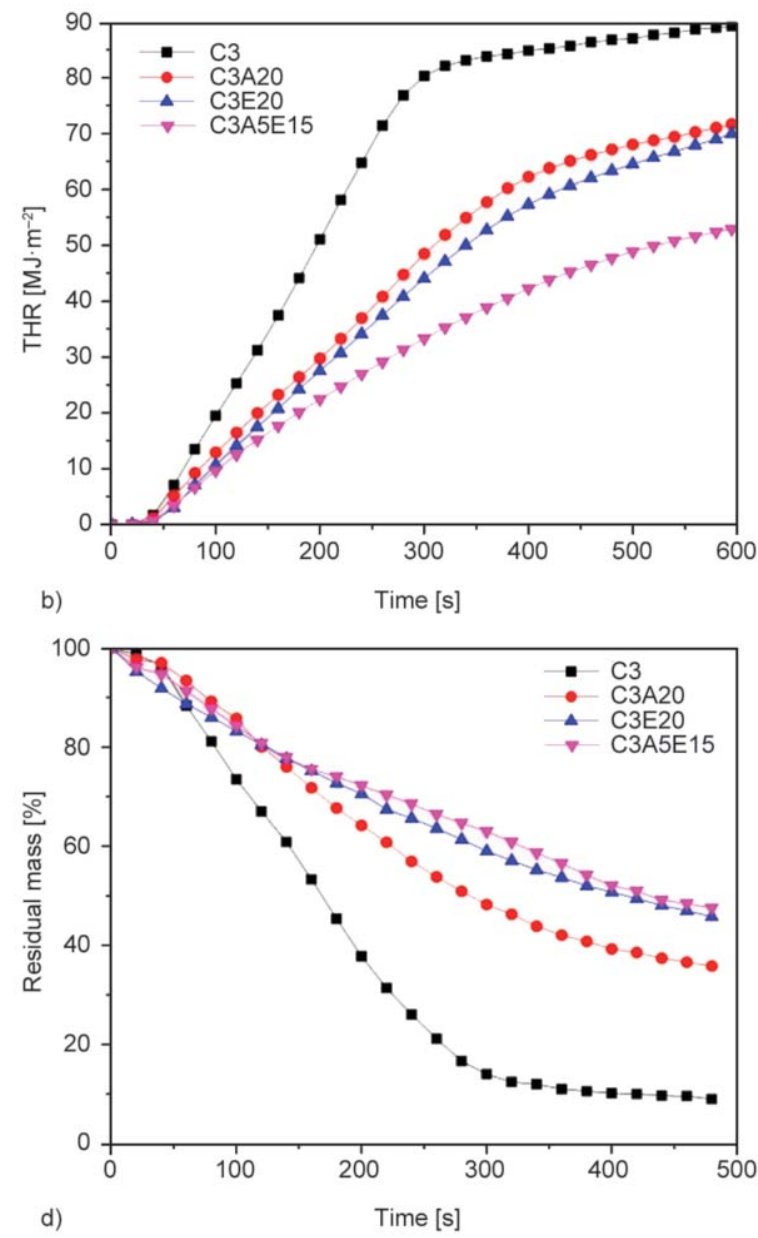

Figure 5. (a) HRR, (b) THR, (c) TSR and (d) residual mass curves for treated and untreated WF/PP composite (viz. WF/PP/CB 60/40/3 (C3), PP/WF/CB/APP 60/40/3/20 (C3A20), PP/WF/CB/EG 60/40/3/20 (C3E20) and $\mathrm{PP} / \mathrm{WF} / \mathrm{CB} / \mathrm{APP} / \mathrm{EG} 60 / 40 / 3 / 5 / 15$ (C3A5E15). Reprinted from [76]. 
(57/18)-based composites, containing APP (12\%), $4 \%$ MEL, $4 \%$ DPER. The presence of these nanofillers improved the overall mechanical properties when compared to the neat WPC, with the flame resistance performance being enhanced as indicated by the LOI values obtained; increasing from $\sim 18.1$ to $\sim 34.5 \%$ (for TD) and $\sim 38.1 \%$ (for MD), while a UL-94 rating of V-0 was obtained. Both MD- and TD-based systems showed reductions in pHRR, TSR, and EHC. In the case of MD, the exceptional performance was ascribed to the fact that $\mathrm{MnO}_{2}$ catalyzed IFR to dehydrate and produced char as well as accelerating the oxidation-reduction reaction of the burning process. However, TD-based
WPC exhibited good smoke suppression with a steady COP, which was $\sim 77 \%$ less than that of the neat WPC. Biochar was also introduced into the WF composites, hoping to enhance the non-flammability and the mechanical properties of the resulting WPC products [94]. The presence of biochar did not improve the flammability resistance of the WPC products, but additional FRs exhibited enhanced nonflammability of the resulting composites without significantly affecting the resulting mechanical properties. With the addition of ATH and MH to WPC/ biochar composite, it was found that the LOI values increased from flammable material to a first level non-flammable material.

Table 4. Mechanical properties of wood plastic composites containing FRs.

\begin{tabular}{|c|c|c|c|c|c|c|c|}
\hline Formulation & $\begin{array}{c}\text { Tensile } \\
\text { strength } \\
\text { [MPa] }\end{array}$ & $\begin{array}{c}\text { Tensile } \\
\text { modulus } \\
\text { [GPa] }\end{array}$ & $\begin{array}{l}\text { Flexural } \\
\text { strength } \\
\text { [MPa] }\end{array}$ & $\begin{array}{c}\text { Flexural } \\
\text { modulus } \\
\text { [GPa] }\end{array}$ & $\begin{array}{l}\text { Impact } \\
\text { strength }\end{array}$ & Verdict & Refs. \\
\hline $\begin{array}{l}\text { Recycled HDPE filled with } \\
\text { rice husks, and saw dust } \\
(50-70 \%) \text { with additives } \\
\text { (sodium metasilicate and ZB } \\
\text { as FRs; IRGANOX } 1010 \\
\text { and IRGAFOS } 168 \text { as an- } \\
\text { tioxidants) }\end{array}$ & $6.6-11.6$ & $1.30-1.35$ & $16.9-17.6$ & $2.33-2.52$ & $2.56-3.32^{\mathrm{a}}$ & $\begin{array}{l}\text { The presence of both antioxi- } \\
\text { dants and FRs enhances the me- } \\
\text { chanical properties as well as } \\
\text { durability performance of the } \\
\text { WPC }\end{array}$ & {$[96]$} \\
\hline $\begin{array}{l}\text { PE filled with } 50 \mathrm{wt} \% \mathrm{WF} \\
\text { and } 10 \% \text { of various FRs }\end{array}$ & - & - & $30-36$ & $3.6-5.2$ & - & $\begin{array}{l}\text { All FRs enhanced the fire per- } \\
\text { formance } \\
\text { Despite other FRs not signifi- } \\
\text { cantly influencing the mechan- } \\
\text { ical properties, ZB-based en- } \\
\text { hanced flexural modulus }\end{array}$ & [6] \\
\hline $\begin{array}{l}\text { HDPE filled with WFs (31- } \\
38 \mathrm{wt} \%) \text { boron-based FRs } \\
(4-12 \mathrm{wt} \%)\end{array}$ & $16.4-24.9$ & - & $54.3-68.4$ & $8.16-9.08$ & $22.8-34.5^{b}$ & $\begin{array}{l}\text { Low content }(2 \mathrm{wt} \%) \text { of boron- } \\
\text { based FRs had positive impact } \\
\text { on mechanical properties }\end{array}$ & [98] \\
\hline $\begin{array}{l}\mathrm{PP} \text { filled with } 25-50 \mathrm{wt} \% \\
\mathrm{WF} \text { and } 25 \% \text { of various FRs }\end{array}$ & $23.0-34.8$ & $2.2-3.1$ & $48.2-66.4$ & $2.5-3.7$ & $57-165^{b}$ & $\begin{array}{l}\text { No significant influence on the } \\
\text { mechanical properties, but MH- } \\
\text { based WPC exhibited better } \\
\text { flame resistance performance }\end{array}$ & {$[97]$} \\
\hline PP filled with $25 \%$ APP & 15.68 & - & 31.30 & 1.65 & $16.24^{b}$ & \multirow{2}{*}{$\begin{array}{l}\text { No significant influence on the } \\
\text { mechanical properties of the } \\
\text { composite when compared to } \\
\text { neat WPC, while maintaining } \\
\text { excellent flame resistance prop- } \\
\text { erties }\end{array}$} & \multirow[b]{2}{*}{ [99] } \\
\hline $\begin{array}{l}\text { PP filled with } 25 \% \text { APP and } \\
\text { other FRs } 3 \% \text { (ZB, BX, BA } \\
\text { and mixture of BX/BA) }\end{array}$ & $18.28-20.28$ & - & $\begin{array}{l}34.76- \\
37.50\end{array}$ & $1.70-192$ & $13.97-15.27^{\mathrm{b}}$ & & \\
\hline $\begin{array}{l}\text { PVC filled with and WF } \\
(60 \%) \text { various FRs (i.e., DAP } \\
1.5, \text { TPP } 2.5 \text { and AHP } 20)\end{array}$ & & & $45-62$ & $5.30-5.57$ & $4.72-6.02^{\mathrm{a}}$ & $\begin{array}{l}\text { Flexural and impact properties } \\
\text { were improved at low FRs con- } \\
\text { tent, while flame retardant per- } \\
\text { formance was enhanced }\end{array}$ & {$[61]$} \\
\hline $\begin{array}{l}\text { PVC filled with } 40 \text { phr WF } \\
\text { and sefmade IFR (composed } \\
\text { of guanylurea phosphate, } \\
\text { boric acid and other addi- } \\
\text { tives) }\end{array}$ & - & - & $72.4-147.4$ & $6.5-11.5$ & $5.5-14.9^{\mathrm{a}}$ & $\begin{array}{l}\text { The presence of IFRs slightly } \\
\text { decreased the mechanical prop- } \\
\text { erties, whereas good flame re- } \\
\text { sistance performance was ob- } \\
\text { tained }\end{array}$ & {$[18]$} \\
\hline $\begin{array}{l}\text { PLA filled with } 10 \% \text { oxi- } \\
\text { dized WFs and } 10 \% \text { APP }\end{array}$ & $30.7-32.7$ & $2.01-2.02$ & - & - & - & Toughness was improved & {$[10]$} \\
\hline
\end{tabular}

aunits in $\mathrm{kJ} / \mathrm{m}^{2}$

${ }^{b}$ units in $\mathrm{J} / \mathrm{m}$ 


\section{Mechanical properties}

Similar to any polymeric reinforced composite system, it is recognized that the mechanical properties of WPCs, are directly dependent on the properties of the polymer matrix, particle content, geometry of particles, dispersion of the particles, interfacial interaction, as well as the processing technique [86, 95-98]. Table 4 shows a list of the mechanical properties of WPCs containing FRs.

\subsection{Metal hydroxides}

Metal hydroxide, typically aluminum-based or magnesium-based FRs, are often employed as effective FRs for polyolefins $[6,90]$. In hydrate-forms, aluminum-based and magnesium-based FRs decompose into water vapor, which in turn dilutes combustible gases. The heat required for the production of water vapor also acts to promote the flame retardancy of these FRs. Metal oxides are good adsorbents for carbon materials; hence they are excellent smoke reducers. Elsewhere, it was found that the addition of aluminum hydroxide (ATH) to PP/WF composite decreased the tensile strength and the elastic modulus of the resulting composite [54]. It was found that an increase in aluminum hydroxide content, from 5 to $10 \mathrm{wt} \%$, led to similar tensile strength. The size of magnesium hydroxide (MH) was found to play a critical role in the flame retarding behavior and the mechanical properties of the resulting composites [55]. As expected, ultrafine $\mathrm{MH}$ particles enhanced the tensile strength and the elongation-at-break up to an $\mathrm{MH}$ content of $30 \mathrm{wt} \%$ due to the better dispersion and interaction that are often obtained with the use of $\mathrm{MH}$ particles. It was found that ordinarily sized $\mathrm{MH}$ particles resulted in a significant decrease in the tensile strength and the elongation-at-break of the resulting composites. Despite an increase in the WF content, enhancing the flame retardancy of $\mathrm{WF} / \mathrm{PP} / \mathrm{MH}$ $60 / 28 / 10$, good mechanical properties were obtained at low WF (40 wt\%) in the presence of MH [29]. It was, found that the modulus of rupture (MOR) and the modulus of elasticity (MOE) increased from 17.5 and $1816 \mathrm{MPa}$ to 19.0 and $2085 \mathrm{MPa}$, respectively. However, MOR decreased to $11.8 \mathrm{MPa}$, and MOE increased to $1840 \mathrm{MPa}$ when the WF content reached $60 \mathrm{wt} \%$ (which exhibited best fire performance). On the other hand, the amount of the FR was also found to adversely affect the mechanical properties [90]. Wang et al. [90] reported that the addition of $30 \mathrm{wt} \%$ of ATH decreased the MOR by $\sim 15 \%$ and increased the MOE by $\sim 22 \%$, but it did not influence the impact strength of the composite material. This was attributed to the stronger interfacial adhesion, better dispersion, and variation in the PP crystallinity. A comparative study of the ATH and MH with halogenated-based FRs was conducted by Zhang et al. [59]. It was found that the MH samples had MOE values similar to the control sample, however, ATH and 1,2-bis(pentabromophenyl) ethane, retained $\sim 90 \%$ of the original MOE values. The MOR values decreased with the addition of all the investigated FRs. This was due to compromised interfacial adhesion between WF and the host matrix in the presence of FRs. The increase in the ATH from 5 to $10 \mathrm{wt} \%$ resulted in the MOE reduction, whereas no reduction was observed for both $\mathrm{MH}$ and 1,2-bis(pentabromophenyl) ethane-based composites. MOR, however, for $\mathrm{MH}$ and ATH decreased with an increase in their contents. Umemura et al. [56] also reported that the addition of ATH resulted in a decrease in the tensile strength but with a slight reduction in the elastic modulus.

\subsection{Phosphorus based materials}

Phosphorus-based FRs are recognized by the presence of phosphorus, which includes: organic phosphonates, phosphonates, phosphate-and-halogen-containing compounds, ammonium polyphosphate (APP), and red phosphorus (RP), in their chemical structure $[7,100]$. Since the flame retardancy of phosphorusbased FRs depends on the type and content, hence, these parameters play critical roles in the resulting mechanical properties of the product [100]. One of the most used phosphorus-based FRs is ammonium polyphosphate (APP) in WPC. The major drawback of APP in WPC is the deterioration of the resulting mechanical properties due to the lack of strong adhesion between APP and WPC [91]. Wang et al. [91] prepared WPC from MAPP, poplar wood flour, and APP by using a twin-screw extruder. They found that despite the presence of $25 \%$ APP that resulted in improved flame retardancy of the resulting composite materials, the mechanical properties were adversely affected. The presence of the phosphorus-based FRs, can cause an interaction with the compatibilizers, often used for enhancement of adhesion between wood particles and host polymeric material; hence, there will be no effective stress transfer between these components, which can result in a detrimental effect on the mechanical properties when compared 
to the neat WPC [7]. However, Li et al. [7] reported that the presence of APP slightly reduced the Izod impact, while there was no significant influence on the tensile strength. Similar results were obtained for WPC/melamine phosphate (MP). The authors reported that the use of pentaerythritol (PER), resulted in poor mechanical properties due to the possibility of PER being dispersed at the interface of the wood fibers (WFs) and the compatibilizer (maleic anhydride-grafted-PE (MA-g-PE). This hinders the esterification reactions between the $-\mathrm{OH}$ groups on the wood surface and the anhydride groups on the polyethylene chains of MAPP, which were replaced by the reactions between PER and MA-g-PE. This resulted in a limited adhesion between WFs and PE. A recent study by Pham et al. [60] demonstrated that the phosphorus-type of FR plays a critical role on the mechanical properties. It was found that with the addition of aluminum diethyl phosphinate (OP)
(30 wt \%), the flexural modulus, flexural strength, and the impact strength significantly decreased; however, diammonium phosphate (DAP) $(25 \mathrm{wt} \%)$ slightly reduced the mechanical properties due to the strong interaction between wood and DAP. A novel intumescent FR (IFR) system, containing poly[N4-bis (ethylenediamino)-phenyl phosphonic- N2,N6-bis(ethylenediamino)-1,3,5-triazine- $N$-phenyl phosphonate] (PTPA) and APP for a WF/PP composite, was developed by Guan et al. [101]. A gradual increase in the PTPA content in the WF/PP/APP composite strengthened the composite product. The sample of $20 \%$ ATPA $/ 10 \%$ APP in WF/PP recorded the best mechanical properties, with the flexural modulus reaching a value of $4.4 \mathrm{GPa}$ and an impact strength of $1.8 \mathrm{~kJ} / \mathrm{m}^{2}$. The modification of APP with ethanolamine via ion exchange resulted in an enhanced impact strength due to the good dispersion of the additives [64]. It was reported that the modification of

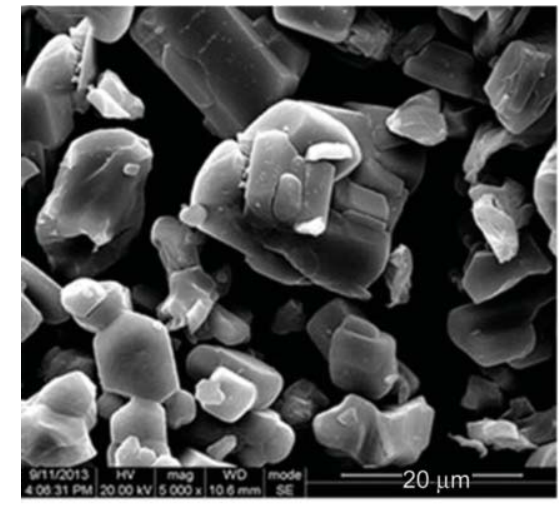

a)

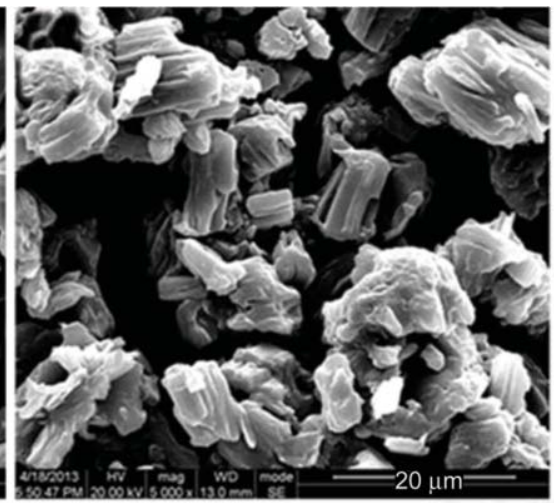

b)

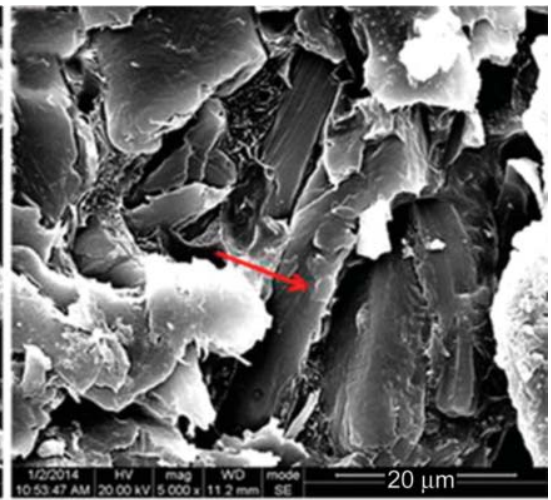

c)

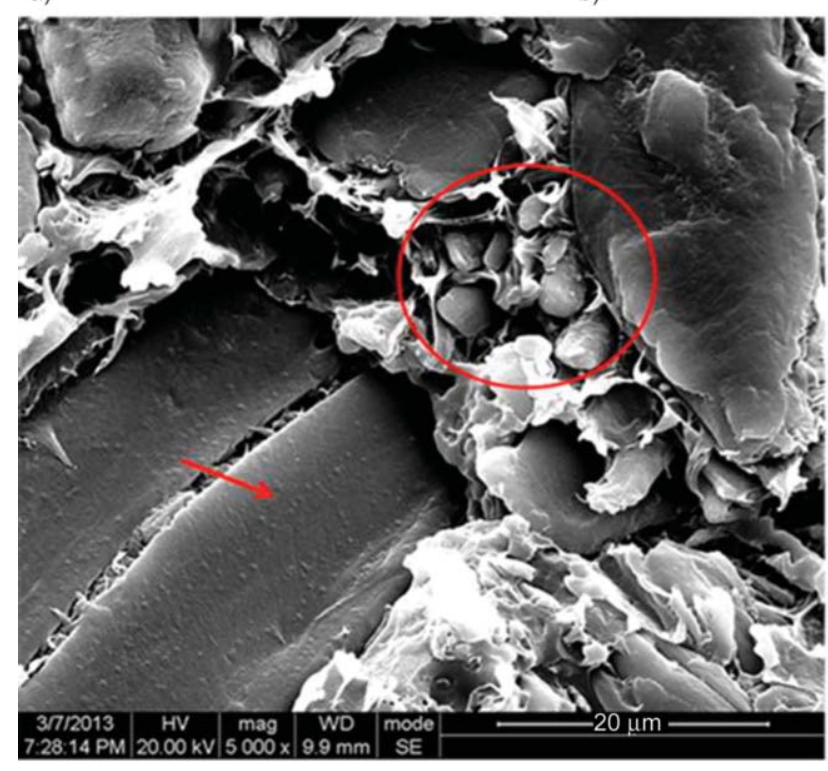

d)

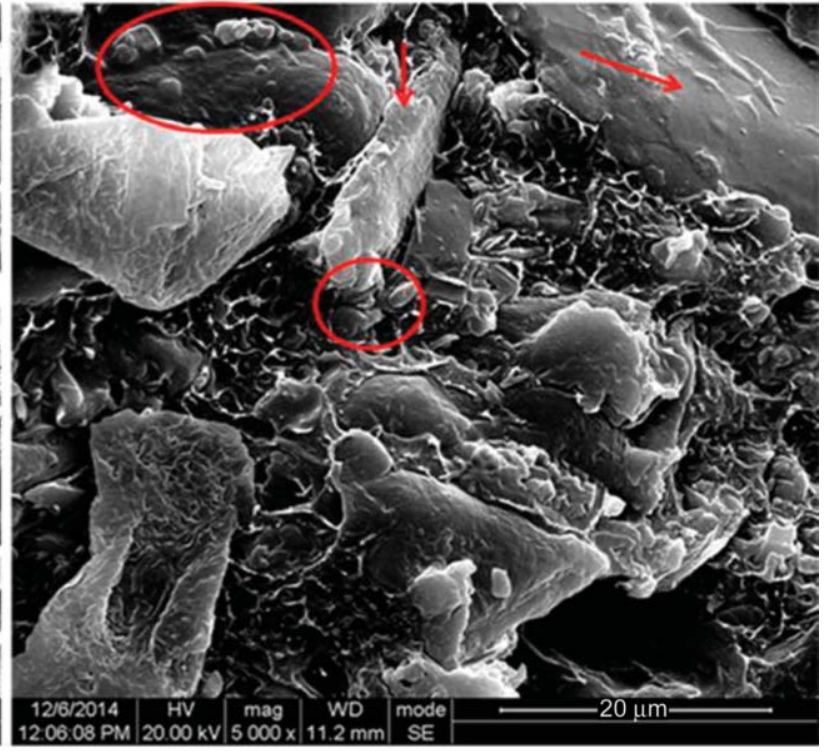

e)

Figure 6. SEM imaged of (a) untreated APP, (b) ethanolamine treated APP, (c) WPC, (d) WPC containing untreated APP and (e) WPC with treated APP. Adapted with permission from [64]. Copyright (2015) American Chemical Society. 
APP resulted in rough surfaces with some of the particles clung to each other (Figure 6b) when compared to smooth surface displayed by neat untreated APP (Figure 6a). In the case of neat WPC, the WFs were well embedded within the matrix, indicating that there was strong adhesion between WFs and the host polymer matrix (Figure 6c). Treatment of APP resulted in particles being well-distributed and embedded within the matrix suggesting good interaction rather than agglomerated APP particles in the fracture surface (indicated by red cycle in Figure 6d), with some voids around WFs (marked by the red arrow in Figure 6d). Treatment of APP improves the interaction between APP (indicated by red cycle in Figure 6e) and WPC (marked by red arrow in Figure 6e), resulting in enhanced mechanical properties compared to untreated APP-based WPCs. This suggests that modification of FRs can be applied to maintain or further improve the resulting mechanical properties of WPC/FR systems.

\subsection{Boron-based FRs}

Boron-based FRs are well known for their capability to produce a large amount of char $[33,69,70]$. Boron is often employed, in combination with zinc, as in zinc borate, in the form of hydrates. Similar to metal hydroxide, the heat required to remove water from zinc borate further contributes to the flame retardancy of these materials. The mechanical properties of the WPCs containing boron-based FRs were found to decrease with an increase in the FRs content. The main concern was the contamination of wood fibers surface by the FRs, hence, a reduction in the interaction between wood and polymeric matrix, even in the presence of the coupling agent or compatibilizer [23]. Fang et al. [70] reported that the WPCs containing zinc-borate exhibited a reduction in the tensile and flexural strength by $\sim 19$ and $\sim 8 \%$, respectively. This was, ascribed to the poor interface compatibility of the ZB with the composite. However, the tensile modulus was found to increase due to an increase in the rigidity of the composite. Ayrilimis et al. [23] studied the effect of zinc borate and the coupling agent content on the mechanical properties of WPC. They reported that tensile strength (TS), modulus of rupture (MOR), and impact strength slightly decreased with an increase in zinc borate (ZB) content; meanwhile, the modulus of elasticity (MOE) was found to increase with ZB content. However, the use of a coupling agent improved the flexural performance of the resulting WPCs as well as the tensile strength. The impact strength also improved up to $4 \mathrm{wt} \%$ MAPP addition and further increase, resulting in the opposite effect (i.e., decreased overall mechanical properties of the resulting WPCs). This was due to the interfacial interaction between wood fibers and the polymer being compromised by the addition of ZB. FRs crystalline deposits contaminated the wood fibers surface (as crystalline particles), thereby suppressing the interfacial bonding between the functional polar groups ( $-\mathrm{OH}$ groups) of wood and MAPP (anhydride groups), which resulted in the poor adhesion between polymer matrix and wood fibers. However, the use of a coupling agent improved adhesion between the wood fibers and the polymer matrix, as confirmed by the wood fiber breakage of the tensile fractured surface of WPCs. In general, the presence of the boron-based FRs were, found to decrease the mechanical properties of the resulting composite materials, regardless of the polymer matrix, presence of coupling agent, and the processing technique. Nonetheless, Terzi et al. [69] reported that MOE increased by $\sim 91 \%$ for $\mathrm{ZB}, \sim 72 \%$ for $\mathrm{BA}, \sim 49 \%$ for colemanite, $\sim 66.9 \%$ for ulexite, and $\sim 55 \%$ for the tincalconite-based WPC, with $1 \%$ of ethylene acid copolymer as the coupling agent. The MOR values were not significantly influenced by the presence of uxelite, colemanite, and tincalconite, but the biggest improvement of $\sim 18 \%$ was, recorded for the ZB and borax-based samples.

\subsection{Carbon-based materials}

Graphite has been considered as one of the most promising flame retardants. Elsewhere, it was reported that the addition of expandable graphite (EG) to WPCs, led to a reduction in the flexural strength and modulus [92]. The inclusion of $20 \%$ of EG, resulted in $\sim 63 \%$ decrease in the flexural strength when compared to WPC. Similarly, Guo et al. [72] reported that the tensile strength, flexural modulus, and impact strength were reduced with the addition of EG to the WPC. From DMA results, an increase in EG content was reported to reduce the elastic modulus; however, the loss factor peaks and glass transition temperature $\left(T_{\mathrm{g}}\right)$ increased with EG content, indicating that EG and WF induced higher energy dissipation and constrained the mobility of epoxy polymer chains. In the case of the tensile strength, the untreated WFs-based WPCs were found to reduce the tensile strength with 
increases in the EG content relatively to the WF/ epoxy composite. The treatment of WF with $\mathrm{NaOH}$ resulted in enhancement by $\sim 24.77 \%$ due to the stronger interfacial adhesion between WFs and the resin matrix. Furthermore, the elongation-at-break was, improved by $\sim 51.26 \%$ for the treated WF-based samples. EG constrained the load transfer between resin matrix and WFs; hence it reduced the overall tensile properties. The use of recycled polymers to manufacture WPC products, in an effort to reduce the overall cost, has received tremendous interest [102-104]. The comparison of fillers, i.e., graphite, talc, and mica, as reinforcing phases of the recycled polymer-based WPC, was investigated by Ramli et al. [102]. It was, reported that the highest impact strength $\left(6.99 \mathrm{~kJ} / \mathrm{m}^{2}\right)$ was obtained for the graphitebased samples ( 3 phr graphite) because the graphite was able to effectively distribute the applied stress in order to overcome crack.

Graphene nanoplatelets (GNPs) were also introduced into WPC as a reinforcing agent to improve the physicomechanical properties $[80,105]$. The first report on the influence of the GNPs content on the PP/WF WPC was by Sheshmani et al. [80]. It was, found that the tensile strength increased from 26.6 to $31.9 \mathrm{MPa}$ with only $0.8 \%$ GNPs and the tensile modulus increased by $41 \%$. The flexural modulus was also enhanced by $80.6 \%$ and the flexural strength by $114 \%$ with the addition of $0.8 \%$. Similarly, it was found that the addition of $\sim 1 \mathrm{phr}$ GNPs, resulted in enhanced tensile properties, but further increase in the GNPs content $\sim 4 \mathrm{phr}$ decreased the tensile strength and the modulus [105]. The latter results could be attributed to the agglomeration or poor dispersion of the fillers.

Carbon nanotubes (CNTs) are also considered as an excellent reinforcing agent for WPCs [106]. Because of its high aspect ratio and the large surface area of CNTs were found to increase the tensile and flexural strength with an increase in nanoparticle concentration [106]. Functionalized multi-walled carbon nanotubes (MWCNTs) further improved the flexural and tensile strengths more than raw MWCNTs due to enhanced interfacial adhesion between the fillers and $\mathrm{PVC} / \mathrm{WF}$ composite. Furthermore, the tensile and flexural moduli increased with the addition of MWCNTs, with further improvement exhibited by functionalized MWCNTs due to the chemical modification, forming linkages of the CNTs to the polymer, which in turn enhances stress transfer between the polymer and the CNTs. The effect of singlewalled-carbon nanotubes (SWCNTs) on the WPCs mechanical properties was investigated by Kordkheili et al. [107]. It reported that the flexural modulus and strength increased with an increase in the SWCNTs, which were further increased in the presence of the coupling agent, MA- $g$-PE. The impact strength for WPCs, containing: 1, 2, and $3 \mathrm{phr}$, increased by 74 , 111 , and $94 \%$, and the presence of a coupling agent, further enhanced the impact strength.

\subsection{Other materials}

Bamboo charcoal (BC), as a reinforcing agent of WPC, was first reported by Li et al. [108]. It was, reported that the increase in $\mathrm{BC}$ content resulted in an increase in the flexural modulus. This was because of the restriction of the polymer chains, resulting from the LDPE chains entering the BC pores and gaps, thereby increasing the interfacial adhesion. Strong interfacial adhesion was also confirmed by an increase in the flexural strength with an increase in the $\mathrm{BC}$ concentration. Flexural strength increased from 14.1 to $16.9 \mathrm{MPa}$ after the addition of $8 \% \mathrm{BC}$, corresponding to $\sim 19.9 \%$ increment. Moreover, the char residue at $600^{\circ} \mathrm{C}$ was found to increase with increasing content of $\mathrm{BC}$, which can be conducive for flame retardancy of this product. The improvement of char residues is associated with an increase in thermal stability. This is because high char residues hinder the exothermicity of the pyrolysis reactions, reduces volatile gas production, and inhibit the thermal conduction of WPCs. Biochar obtained from wood waste was also utilized to reinforce WPCs [109]. Increasing the content of biochar to $24 \%$ enhanced the composite' tensile/flexural and moduli. With the addition of MD and TD as synergistic agents in WPC/IFR, the mechanical properties were improved [93]. The tensile modulus, flexural strength, and Izod impact strength increased by 71.4, 110, and $66.7 \%$, respectively, for the MD-based samples and by $82.7,112$, and $90.6 \%$ for TD-based samples, respectively.

\subsection{Nanomaterials}

\subsubsection{Organoclays}

Organoclays are also considered as suitable flame retardant materials for thermoplastic-based WPC materials $[62,85,86]$. Organoclays have distinctive properties, such as high surface area and aspect ratio, which are of significance for promoting better 
dispersion as well as mechanical properties of the resulting WPCs. Lee et al. [87] prepared WPC/clay composites by using a twin-screw extruder in the presence of a compatibilizer in order to achieve fully exfoliated clay nanoplatelets. The investigated systems (clay content of 1,3 , and 5\%) exhibited a high degree of clay structures exfoliation due to the presence of the compatibilizer (HDPE grafted with maleic anhydride) and high mechanical shear. It was found that the tensile and flexural moduli of the WPCs, in the presence of clay, was significantly improved, which was attributed to the exfoliation of the clay particles. The high aspect ratio of the clay particles led to a large interfacial area, which in turn enhanced the stress transfer between the matrix and the clay particles. It is worth mentioning that there are maxima contents for the flame retardant filler and the compatibilizer/coupling agent in order to enhance both the mechanical and flame retarding efficiencies of WPC. For instance, Zhao et al. [27] found that the impact strength peaks at $\sim 0.5 \%$ clay and tensile strength at $\sim 1.5 \%$, and a further increase in clay content beyond the optimal amount, led to both of these properties decreasing. In the case of the use of silane as a coupling agent, the tensile strength peaked at $\sim 1.5 \%$ and the impact strength at $\sim 2.5 \%$.

\subsubsection{Other nanofillers}

A comparison between micro-and nanosized $\mathrm{SiO}_{2}$ particles, incorporated via dry and wet dispersion, on the mechanical properties was investigated by Zhou et al. [41]. It was, found that increasing the micro$\mathrm{SiO}_{2}$ size via the dry dispersion technique resulted in a decrease in the storage modulus due to a lack of interfacial bonding between the fillers and HDPE. Meanwhile, micro- $\mathrm{SiO}_{2}$ introduced by wet dispersion enhanced the storage modulus because of the homogeneous distribution and strong interfacial bonding, such that the rigidity of micron- $\mathrm{SiO}_{2}$ was well exploited. However, nano- $\mathrm{SiO}_{2}$ incorporated via dry and wet dispersion displayed higher storage modulus than the unfilled WPCs, but the wet dispersion resulted in a higher storage modulus when compared to the dry dispersion technique. This is attributed to the strong interfacial adhesion and the uniform dispersion, which promoted efficient stress transfer from the WPCs to the nano- $\mathrm{SiO}_{2}$ inclusion.

The improvement of the mechanical properties of CNC-APP was a result of the good dispersion and strong interfacial adhesion [89]. It was reported that both the tensile strength and modulus increased with an increase in the APP-CNC content. The tensile modulus increased to $75.9 \%$ and tensile strength to $42.7 \%$ because of the $\mathrm{CNC}$, acting as dual-modifier for dispersion and interfacial bonding for APP via the ionic bond and hydrogen bond, hence improving the overall mechanical properties of the resulting WPCs.

\subsection{Synergistic systems}

\subsubsection{Metal hydroxide-based and others}

Zhang et al. [94] reported that the inclusion of magnesium hydroxide (MH) into a biochar-based WPC, led to an increase in the tensile strength, up to $\sim 30 \mathrm{wt} \%$ of $\mathrm{MH}$, with the impact strength increasing overall investigated $\mathrm{MH}$ contents $(10-40 \mathrm{wt} \%)$. However, the inclusion of aluminum hydroxide (ATH) resulted in a slight decrease in the tensile strength and the impact strength. Notably, MH-based WPC exhibited better flame resistance performance than the ATH-based composites.

\subsubsection{Phosphorus-based and others}

It was recognized that the inclusion of a second filler or compound is to overcome the limitations of the other filler or compound. The presence of the second filler is often found to enhance not only the flame retardancy of the resulting composite material but also to improve the overall mechanical properties [47]. This is, attributed to the positive synergistic effect between the fillers. For instance, Wang et al. [91] reported that an additional nanofiller (i.e., zeolites) into WPC/APP system improved the overall mechanical properties due to the zeolite particles acting as a reinforcing agent, which bound the polymer chains, hence restricting the mobility of the chains. Kalali et al. [47] reported that the addition of APP to WPC, reduced the tensile and impact strengths by $\sim 10.1$ and $\sim 32.8 \%$, respectively. However, the inclusion of phytic acid-modified layered double hydroxides (PhLDHs) in the system (WPC/APP) enhanced the mechanical properties. The addition of $1 \mathrm{wt} \% \mathrm{Ph}-\mathrm{LDHs}$, resulted in the tensile strength, tensile strain, and impact strength by $\sim 13.8, \sim 17.2$, and $\sim 26.8 \%$, respectively. The presence of the second compounds was also reported in the literature to adversely affect the mechanical properties of the resulting WPC materials. Li et al. [63] reported that besides the combination of phosphorus-based FRs (AHP and MP) improving the overall flame retardancy of the resulting WPC material, the resulting mechanical properties were 
poor. It was, found that the increase in the FRs content resulted in decreases in the tensile strength and flexural strength. The type of FR also plays a major role in the resulting mechanical properties. Elsewhere, it was reported that the combination between APP, MP, and PER resulted in drastic decreases in mechanical properties [7]. This was, attributed to a lack of interaction between FRs and WPC, with PER being dispersed at the interface of the WFs and the compatibilizer used and hence, reducing the interaction between WFs and the host polymeric matrix. Zhao et al. [22] reported on the fact that there was slight a decrease by $\sim 3.5 \mathrm{MPa}$ in tensile strength and the flexural strength increased by $\sim 11 \%$ for the WF/ $\mathrm{PP}$ containing aluminum phosphinate (AP)/melamine cyanurate (MCA), in a 5:1 ratio in comparison with WF/PP composite. This sample also exhibited the highest LOI value $(29.5 \%)$ and V-0 rating without dripping.

Recently, Zhang et al. [49] reported on the presence of silica in WF/PP/APP, which counteracted the detrimental effect of APP on the mechanical properties of the resulting product. It was found that the presence of silica particles increased the tensile strength, with optimal concentration being $4 \mathrm{phr}$, after which the opposite effect became more dominant due to filler agglomeration. However, an increase in silica and APP caused a decrease in the impact strength due to the less amount of the polymer matrix, responsible for absorbing impact energy. Increases in the tensile strength and the flexural modulus were obtained by decorating APP with amino glycerine, as reported by $\mathrm{Xu}$ et al. [35]. This is due to the strong interfacial adhesion and the good dispersion caused by the decoration with amino glycerine.

\subsubsection{Boron and others}

Treatment of WFs with a mixture of borax (BX) and boric acid (BA) incorporated into WPCs, resulted in decreasing MOR and MOE values when compared with samples without BA and BX [110]. This was, ascribed to the treatment that promoted hydrolysis of the WFs, hence, causing a loss in strength. The combination of APP with either BX or BA and the combination of both, as intumescent FRs, was investigated by Kurt and Mengeloğlu [99]. It was, found that WPC containing 25\% APP had significantly lower MOR when compared to the neat WPC. However, the inclusion of $\mathrm{ZB}, \mathrm{BA}$, and $\mathrm{BX}$ into $\mathrm{WPC} / 25 \% \mathrm{APP}$, did not affect the MOR when compared to the neat
WPC, even when both BA and BX mixture was introduced into the system. It was found that the increase in BA/BX mixture slightly decreased the MOR and $\mathrm{MOE}$ values, while the tensile strength and the burning rate were not significantly influenced. MOE was found to improve with the addition of $\mathrm{ZB}, \mathrm{BA}$, and $\mathrm{BX}$ or a mixture of $\mathrm{BA} / \mathrm{BX}$ in the WPC/APP composite, but the tensile strength and impact strength were not affected by their addition. This was ascribed to the improved crystalline formation in the samples. It was, found that the addition of $3 \%$ of either ZB, $\mathrm{BA}$, or $\mathrm{BX}$ and mixture of $\mathrm{BA} / \mathrm{BX}$ is sufficient to compensate for the decrease in mechanical properties imposed by APP without losing the flame resistance performance of the composites. Cavdar et al. [32] found that WFs impregnated in BA/BX mixture adversely affected the tensile strength due to the poor interface between wood particulates and the host polymeric material, thus resulting in poor stress transfer. As expected, the tensile moduli increased with FRs treated-WFs loading, while the elongation-atbreak decreased because of the high modulus of the WFs, resulting in a brittle-like composite product. The flexural strength increased with the addition of BA/BX-treated WFs when compared to the control sample. The impregnation of WFs in BA/BX had a positive effect on the flexural modulus, increasing by $\sim 57 \%$ when the WFs loading increased from 20 to $40 \%$. Since the increment of the flexural modulus is associated with the brittleness of the samples, the impact strength was, reduced with an increase in the treated WFs loading. The balance between the coupling agent and FRs into polymer/WFs plays an important role in the resulting mechanical properties [23]. At higher FRs content, crystalline particles are often observed to be deposited on the surface of wood particulates, which limit the wetting WFs with polymer, hence resulting in reducing the overall mechanical properties. Elsewhere, it was reported that despite the presence of coupling agent improving interfacial action between wood and host polymeric material, the inclusion of FRs compromised that interfacial action [23]. The latter is due to FRs coating wood particulates, which in turn, increasing the surface area of the WFs and reducing bonding efficiency. The increase in FRs content resulted in a large amount of crystalline particulate of FRs being deposited on the surface of WFs, which further compromises interfacial bonding. Therefore, fairly low contents of FRs are important in order to conserve strong interfacial interaction 
between WFs and host polymeric material, hence improves the overall properties of the resulting WPCs. It was found that $4 \mathrm{wt} \%$ of coupling agent and $8 \mathrm{wt} \%$ of FRs enhances modulus of rupture, modulus of elasticity, impact, and tensile strength.

\subsubsection{Organoclays and others}

The effect of the combination of two nanofillers on the mechanical properties of WPC was also reported by Deke and Maji [39]. It was, reported that there is a maximum concentration of the second nanofiller in order to achieve excellent mechanical properties. They found that nanoclay 3\%/silica 3\% are optimal contents required to improve the overall mechanical properties. The flexural strength and the modulus increased from 14 and $760 \mathrm{MPa}$ to 37 and $5687 \mathrm{MPa}$, respectively. The tensile strength and the modulus increased from 5.7 and $85 \mathrm{MPa}$ to 40 and $693 \mathrm{MPa}$, whereas hardness increased from 67 to 84 Shore D. This was attributed to the presence of the compatibilizer as well as the nanoparticles acting as reinforcing agents and hence, restricting the mobility of the polymer chains. In another study, these authors used $\mathrm{TiO}_{2}$ particles instead of silica nanoparticles [38]. Similarly, observations were found with $3 \%$ clay/ $3 \% \mathrm{TiO}_{2}$ inclusion, which resulted in a WPC with superior mechanical properties. The flexural strength, flexural modulus, tensile strength, tensile modulus, and hardness were, increased by 168, 571, 495, 661, and $20 \%$, respectively. An increase in Fe particles was found to increase the impact strength of PS/WF/ APP but decreased the overall tensile strength [40].

\section{Durability of WPC}

It is a well-known fact that the sensitivity of polymers and wood to flame limits WPC wider applications. The inclusion of the FRs additives and fillers were, found to enhance the fire performance of WPCs, which in turn qualifies them to meet most of the requirements and regulations to afford their applications in various fields. The presence of polymers in WPC was found to improve the antifungal properties, hence affording their application in construction [111-114]. The often employed FRs contain elements for the nutrition of microorganisms, e.g., sulfur, nitrogen, and phosphorus; hence their protection is essential. The comparison between EG, APP, and the commercially available FR Struktol for flame resistance and the antifungal properties of WPC decking boards was conducted by Naumann et al. [2]
They reported that besides all FR-based composites exhibiting reduced HRR when compared to neat WPC, EG-based composite displayed the highest reduction of HRR, the lowest THE, and the highest amount of char residue and total $\mathrm{CO}$ production (TCOP). It was also found that EG-based composites exhibited the best fungal decay resistance. Moreover, EG-based displayed the highest MOE, and all FRbased composites showed a decrease in MOE after incubation with (T. versicolor, C. puteana and A. alternata) or without fungus of between $20-25 \%$, while Strukol exhibited a $30 \%$ decrease.

Other environmental hazards include moisture, UV degradation, decay, and insect attack, depending on the application of the WPC $[38,113,115]$. García et al. [36] studied the durability tests by using the QUV machine (QUV weathering tester, model QUV/basic), according to EN 927-6 'Exposure of wood coatings to artificial weathering by using fluorescent lamps and water' and color measurements. It was reported that with the addition of light stabilizers, i.e., HALS, Tunivin 111 (1\%) and blend composed of HALS (1\%), UV filter Tinuvin $326(0.5 \%)$, and an antioxidant (Irganox B225 0.2\%). WPCs stabilized with HALS and those stabilized with blend exhibited similar flexural properties. The HAL stabilized types of WPCs, displayed greater color fading. It was reported that the addition of FRs (ATH, melamine cyanurate, APP, and encapsulated APP) worsened the color retention of the WPCs due to the heterogeneity in the blend as well as wood and inorganic particles, increasing the porosity of the samples. With heterogeneity and porosity within and on the surface of the samples, water can penetrate the samples relatively easier and thereby degrading the composite product, especially WFs. The presence of stabilizers in the WPC-containing FRs preserved color more than those samples without stabilizers. As expected, the APP-based WPC exhibited considerably higher color fading than others due to the hygroscopic nature of the APP. It was also demonstrated that the coating of the samples, i.e., ATH-based WPCs as well as ATHbased WPCs containing stabilizer in this case, with LDPE film, resulted in no color change after 300 hours of weathering and very minimal color change after 600 hours. This indicates the fact that the coating of the samples is the best solution for sample protection against weathering. The best overall performance was observed for ATH as FR and a blend of stabilizers. Boron-based FRs have good flame 
retarding efficacy and provide sufficient protection against wood-destroying microorganisms [110]. Elsewhere, it was found that a mixture of borate and borax WFS treatment, combined with vinyl monomers, improved decay resistance and fire performance of the WPC products [110]. Polymers are also found to play a significant role in the durability of WPC [31]. Polystyrene and polypropylene-based WPC were found to exhibit the least mechanical properties losses from natural weathering for a duration of 90 days when compared to LDPE and PVC-based WPC products [31]. Hemmati and Garmabi studied the durability and biological properties for outdoor applications by developing WPCs that consisted of different additives, i.e., pigments, FRs, UV absorber, and antifungal agent by using a counter-rotating twin-screw extruder [114]. Besides the composites showing enhanced fire resistance, $\mathrm{MH}$ containing samples exhibited no growth and reproduction for all tested fungi, (viz: Lentinus edodes, Pleurotus eryngii, as well as both Trichoderma sp. \& Lentinus edodes and Trichoderma sp. \& Pleurotus eryngii).

Terzi et al. [69] investigated the effect of artificial weathering on the flame resistance property of the WPC containing various FRs. They found that TTI was shorter after weathering, except for $\mathrm{MH}$-containing WPCs. ZB-based WPCs TTI reduced by $12 \%$, while $\mathrm{MH}$ ones increase by $13.5 \%$. Weathering process adversely affects the flame-resistance properties, viz: pHRR, THR, FGI, AEHOC, and ASEA, with the impact depending on the FR-type. It was reported that only $\mathrm{MH}$, exhibited immunity to weathering with regard to the fire testing performance.

Wood products for exterior (or even interior) environments are important to show durability in humid or water, in the case of rainfall. Therefore, a leaching test has also to be conducted in order to ensure that the incorporated additives are not leaching out; hence, they will still perform well under their required applications. FR's leaching during service was mimicked by immersing samples in distilled water according to AWPA E11-97 standard method without stirring process by Cavdar et al. [32]. The unleached samples exhibited LOI values of between 20.75-24.00, and the leached LOI values of between 20.50-24.00 were obtained. This clearly indicates the fact that the leaching of the samples prepared from WFs and treated separately with either BA or $\mathrm{BX}$ as well as their mixture did not affect their flame resistance efficiencies.

\section{Comparison between flammability properties and mechanical properties}

The addition of the additives into WFs/polymer composites is the common practice to enhance the resulting properties especially looking on the application side. The addition of FRs has been recognized as an important aspect with regard to the application of the WPCs in building construction where public fire safety is of importance as well as mechanical properties. In every composite system, dispersion of the filler and interfacial adhesion between the filler and the host matrix play an important role in allowing stress transfer between the components, hence resulting in improved overall mechanical properties. Coupling agent and/or treatment of WFs are often used in WPCs to enhance both dispersion and interfacial interaction between WFs and host matrix, but the addition of FRs complicates the whole system. FRs have a tendency to be deposited as crystalline particles on the surface of the WFs or interact with host polymeric material, which in turn compromises interfacial adhesion, hence detrimental affect mechanical properties. In each system, there are optimal FRs and coupling agent contents in order to strike a balance between mechanical and fireproof of the WPCs, as summarized in Table 5. In addition, most FRs can adversely affect elastic properties, but the balance can be obtained by adding the second filler to compensate for these shortcomings. The optimal concentration of the FRs, coupling agent, and secondary filler yield balanced mechanical properties and flame retardancy of the WPCs systems. It is worth mentioning that the obtained mechanical properties and flame retardancy may be suitable for certain applications; hence every system has to be manufactured in accordance with the intended purpose.

\section{The future of flame retardant WPCs research}

The major market for wood-plastic composites is found in the building and automotive industries. According to the global market outlook for WPC, by 2021, the annual turnover can reach 5.84 billion USD (https://www.grandviewresearch.com/industryanalysis/wood-plastic-composites-market, Market Analysis Report). The increase in WPC market is, driven by the major end-users, including the building \& construction products, e.g., decking, molding \& and siding fencing, and automotive components. Therefore, high performance, low maintenance, and 
Table 5. Selected studies based on comparison between flame retardancy and mechanical properties of WPCs.

\begin{tabular}{|c|c|c|c|c|}
\hline Composition & Flammability properties & Mechanical properties & Verdict & Refs. \\
\hline PP/WF (50/50) & \multirow{3}{*}{$\begin{array}{l}\text { AHP-based and TPP-based } \\
\text { system reduced burning } \\
\text { rate from } 28.7 \text { to } 20.8 \text { and } \\
11.5 \mathrm{~mm} / \mathrm{min} \text {, respectively } \\
\text { satisfy UL-94 HB standard. }\end{array}$} & \multirow{3}{*}{$\begin{array}{l}\text { The addition of } 30 \% \text { FRs (TPP and } \\
\text { AHP) resulted in a decrease in Flexural } \\
\text { strength and unnotched impact strength; } \\
\text { however, the flexural modulus was high- } \\
\text { est for AHP-based system compared to } \\
\text { neat WPC and TPP-based system. }\end{array}$} & \multirow{3}{*}{$\begin{array}{l}\text { Depending on the intended } \\
\text { application, one can fabri- } \\
\text { cate a system with accept- } \\
\text { able mechanical properties } \\
\text { while maintaining excel- } \\
\text { lent flame retardancy. }\end{array}$} & \multirow{3}{*}[50]{} \\
\hline $\begin{array}{l}\mathrm{PP} / \mathrm{WF} / \text { aluminum hydrogen } \\
\text { phosphonate (AHP) }(35 / 35 / 30)\end{array}$ & & & & \\
\hline $\begin{array}{l}\text { PP/WF/triphenyl phosphate } \\
\text { (TPP) }(35 / 35 / 30)\end{array}$ & & & & \\
\hline $\mathrm{PP} / \mathrm{WF} / \mathrm{CA}^{\mathrm{a}}(65 / 30 / 5)$ & \multirow{4}{*}{$\begin{array}{l}\mathrm{PP} / \mathrm{WF} / \mathrm{CA}^{\mathrm{a}}(65 / 30 / 5)-\mathrm{APP} \\
+\mathrm{SiO}_{2}(20+10 \mathrm{phr}) \text { ex- } \\
\text { hibited the highest flame } \\
\text { resistance property with } \\
\mathrm{LOI} \text { of } 28.9 \% \text { and pHRR } \\
\text { rection of } 39 \% \text { compared } \\
\text { to neat WPC. }\end{array}$} & \multirow{4}{*}{$\begin{array}{l}\text { Besides the presence of CA, the tensile } \\
\text { strength, elongation at break, and impact } \\
\text { strength decreased with an increase in } \\
\text { APP content. Despite elongation-at- } \\
\text { break and impact strength decreasing } \\
\text { with an increase in silica content, tensile } \\
\text { strength increased up to } 4 \text { phr, after } \\
\text { which opposite prevailed. }\end{array}$} & \multirow{9}{*}{$\begin{array}{l}\text { The use of APP as FRs im- } \\
\text { proves flame retardancy } \\
\text { property than other FRs, } \\
\text { but it negatively affects } \\
\text { mechanical properties, re- } \\
\text { gardless of using either } \\
\text { coupling agent or treating } \\
\text { WFs. }\end{array}$} & \multirow{4}{*}{ [49] } \\
\hline $\begin{array}{l}\mathrm{PP} / \mathrm{WF} / \mathrm{CA}^{\mathrm{a}}(65 / 30 / 5)-\mathrm{APP} \\
20 \mathrm{phr}\end{array}$ & & & & \\
\hline $\begin{array}{l}\mathrm{PP} / \mathrm{WF} / \mathrm{CA}^{\mathrm{a}}(65 / 30 / 5)-\mathrm{APP} \\
30 \mathrm{phr}\end{array}$ & & & & \\
\hline $\begin{array}{l}\mathrm{PP} / \mathrm{WF} / \mathrm{CA}^{\mathrm{a}}(65 / 30 / 5)-\mathrm{APP}+ \\
\mathrm{SiO}_{2}(20+10 \mathrm{phr})\end{array}$ & & & & \\
\hline PLA/WF/PEG (80/10/10) & \multirow{5}{*}{$\begin{array}{l}\text { PLA/oxidized WF/PEG } \\
(80 / 10 / 10)-A P P 10 \text { phr dis- } \\
\text { played superior flammabil- } \\
\text { ity retardancy reaching } \\
\text { LOI of } 30.6 \% \text { and UL-94 } \\
\text { V-0 rating as well as. }\end{array}$} & \multirow{5}{*}{$\begin{array}{l}\text { Oxidation of WFs promoted interaction } \\
\text { with PLA, hence improved tensile elon- } \\
\text { gation to } \sim 73 \% \text {; however, the addition of } \\
10 \text { phr APP drastically reduced the over- } \\
\text { all mechanical properties of the compos- } \\
\text { ite product. }\end{array}$} & & \multirow{5}{*}[10]{} \\
\hline $\begin{array}{l}\text { PLA/oxidized WF/PEG } \\
(80 / 10 / 10)\end{array}$ & & & & \\
\hline 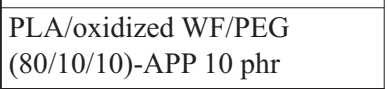 & & & & \\
\hline \begin{tabular}{|l|} 
PLA/oxidized WF/PEG \\
$(80 / 10 / 10)$
\end{tabular} & & & & \\
\hline PLA (100)-APP $10 \mathrm{phr}$ & & & & \\
\hline PE (100) & \multirow{7}{*}{$\begin{array}{l}\text { The presence of WFs re- } \\
\text { duced pHRR of PE by } 75 \% \\
\text { and THR by } 48 \% \text {. } \\
\text { With the addition of } 10 \% \\
\text { FRs, flame retardancy prop- } \\
\text { erty of WPC was signifi- } \\
\text { cantly improved depending } \\
\text { on the FR-type (viz., MH } \\
\text { exhibited increased TTI, } \\
\text { with best improvements ob- } \\
\text { served in pHRR and } \\
\text { aveHRR after } 60 \text { s, but } \\
\text { worst THR was obtained; } \\
\text { ZB performed worse as FR; } \\
\text { melamine phosphate per- } \\
\text { formed neither worse nor } \\
\text { better as FRs, and APP ex- } \\
\text { hibiting most reduction } \\
\text { pHRR and OI). }\end{array}$} & \multirow{7}{*}{$\begin{array}{l}\text { Best mechanical properties were ob- } \\
\text { tained for the ZB-based system. }\end{array}$} & \multirow{7}{*}{$\begin{array}{l}\text { The obtained results make } \\
\text { it difficult to conclude } \\
\text { which FR system is the } \\
\text { best because even for FRs } \\
\text { having the same mode of } \\
\text { action still exhibit different } \\
\text { flame retardancy perform- } \\
\text { ance; meanwhile mechani- } \\
\text { cal properties are often } \\
\text { worst for FRs that dis- } \\
\text { played excellent flame re- } \\
\text { tardancy in WPCs. }\end{array}$} & \multirow{7}{*}{ [6] } \\
\hline $\begin{array}{l}\text { PE/WF/Lubricant } \\
\text { (TPW113,Stow, OH) 45/50/5 }\end{array}$ & & & & \\
\hline $\begin{array}{l}\text { PE/WF/Lubricant } \\
\text { (TPW113,Stow, OH) 35/60/5 }\end{array}$ & & & & \\
\hline $\begin{array}{l}\text { PE/WF/Lubricant } \\
\text { (TPW113,Stow, OH)/MH } \\
35 / 50 / 5 / 10\end{array}$ & & & & \\
\hline $\begin{array}{l}\mathrm{PE} / \mathrm{WF} / \text { Lubricant } \\
(\mathrm{TPW} 113, \text { Stow, OH)/ZB } \\
35 / 50 / 5 / 10\end{array}$ & & & & \\
\hline $\begin{array}{l}\text { PE/WF/Lubricant } \\
\text { (TPW113,Stow, OH)/MP } \\
35 / 50 / 5 / 10\end{array}$ & & & & \\
\hline $\begin{array}{l}\text { PE/WF/Lubricant } \\
\text { (TPW113,Stow, OH)/APP } \\
\text { 35/50/5/10 }\end{array}$ & & & & \\
\hline $\begin{array}{l}\mathrm{PP}(58,48,38) / \mathrm{WF} \\
(40,50,60) / \mathrm{MAPP}(2)\end{array}$ & \multirow{4}{*}{$\begin{array}{l}\text { An increase in WFs im- } \\
\text { proved overall flame retar- } \\
\text { dancy performance, which } \\
\text { further enhanced with the } \\
\text { addition of different FRs. } \\
\text { APP displayed the highest } \\
\text { fire resistance performance } \\
\text { followed by ZB, and lastly } \\
\text { by MH. }\end{array}$} & \multirow{4}{*}{$\begin{array}{l}\text { The increase in WFs decreased modulus } \\
\text { of rupture (MOR) even in the presence } \\
\text { of } 10 \mathrm{phr} \text { FRs, whereas MOE increased } \\
\text { at } 40 \mathrm{wt} \% \mathrm{WFs} \text { until } 50 \mathrm{wt} \% \text {, the de- } \\
\text { creased at } 60 \% \text {. } \\
\text { ZB displayed superior mechanical prop- } \\
\text { erties with the worst observed for APP. }\end{array}$} & \multirow{4}{*}{$\begin{array}{l}\text { The optimal concentration } \\
\text { of the composite con- } \\
\text { stituents is often required } \\
\text { in order to achieve the de- } \\
\text { sired mechanical and flame } \\
\text { retardancy properties. }\end{array}$} & \multirow{4}{*}{ [29] } \\
\hline $\begin{array}{l}\mathrm{PP}(58,48,38) / \mathrm{WF} \\
(40,50,60) / \mathrm{MAPP}(2)-10 \mathrm{phr} \\
\mathrm{ZB}\end{array}$ & & & & \\
\hline $\begin{array}{l}\mathrm{PP}(58,48,38) / \mathrm{WF} \\
(40,50,60) / \mathrm{MAPP}(2)-10 \mathrm{phr} \\
\mathrm{MH}\end{array}$ & & & & \\
\hline $\begin{array}{l}\mathrm{PP}(58,48,38) / \mathrm{WF} \\
(40,50,60) / \mathrm{MAPP}(2)-10 \mathrm{phr} \\
\text { APP }\end{array}$ & & & & \\
\hline
\end{tabular}


Table 5. Continuous (1).

\begin{tabular}{|c|c|c|c|c|}
\hline Composition & lammability properties & Mechanical properties & Verdict & Refs. \\
\hline HDPE/WF/wax 77/20/3 & \multirow{8}{*}{$\begin{array}{l}\text { Increase in untreated and } \\
\text { treated WFs resulted in an } \\
\text { increase in LOI values } \\
\text { while decreasing the burn- } \\
\text { ing rate of the samples. } \\
\text { BX treatment resulted in } \\
\text { the best flame retardancy } \\
\text { property when compared to } \\
\text { BA and BA +BX system. }\end{array}$} & \multirow{8}{*}{$\begin{array}{l}\text { Tensile strength was improved for borax } \\
\text { (BX) treated WFs-based system, but } \\
\text { flexural strength increased for BX and } \\
\text { BA+BX treated WFs based systems. } \\
\text { Tensile modulus and flexural modulus } \\
\text { were improved by the presence of un- } \\
\text { treated WFs as well as treated WFs, } \\
\text { whereas notched impact strength was re- } \\
\text { duced. }\end{array}$} & \multirow{8}{*}{$\begin{array}{l}\text { BX treated WFs resulted in } \\
\text { the best mechanical and } \\
\text { fire resistance perform- } \\
\text { ance. } \\
\text { Treatment of WFs seems to } \\
\text { be a reliable system to } \\
\text { avoid deposition of the FRs } \\
\text { on the surface of WF in } \\
\text { order to avoid detrimental- } \\
\text { ly effect on the mechanical } \\
\text { properties by limiting inter- } \\
\text { facial adhesion between } \\
\text { the host polymeric material } \\
\text { and WFs. }\end{array}$} & \multirow{8}{*}[32]{} \\
\hline $\begin{array}{l}\text { HDPE/ BA treated WF/wax } \\
77 / 20 / 3\end{array}$ & & & & \\
\hline $\begin{array}{l}\text { HDPE/BX treated WF/wax } \\
77 / 20 / 3\end{array}$ & & & & \\
\hline $\begin{array}{l}\text { HDPE/BA+BX treated } \\
\text { WF/wax } 77 / 20 / 3\end{array}$ & & & & \\
\hline HDPE/WF/wax 57/40/3 & & & & \\
\hline $\begin{array}{l}\text { HDPE/ BA treated WF/wax } \\
57 / 40 / 3\end{array}$ & & & & \\
\hline $\begin{array}{l}\text { HDPE/BX treated WF/wax } \\
57 / 40 / 3\end{array}$ & & & & \\
\hline $\begin{array}{l}\mathrm{HDPE} / \mathrm{BA}+\mathrm{BX} \text { treated } \\
\mathrm{WF} / \text { wax } 57 / 40 / 3\end{array}$ & & & & \\
\hline $\begin{array}{l}\mathrm{PVC} 100 \% \text {-WF } 70 \mathrm{phr} / 5 \mathrm{phr} \\
\mathrm{Pb} \text { thermal stabilizer } / 1.5 \mathrm{phr} \\
\text { processing agent, } 5 \text { polyethyl- } \\
\text { ene }\end{array}$ & \multirow{2}{*}{$\begin{array}{l}\text { Flame retardancy and } \\
\text { smoke suppression were } \\
\text { enhanced through the addi- } \\
\text { tion of clay }\end{array}$} & \multirow{2}{*}{$\begin{array}{l}\text { Tensile strength and impact strength de- } \\
\text { creased with an increase in clay content; } \\
\text { however, the treatment of WFs with } \\
\text { silane enhanced tensile strength (in- } \\
\text { creased from } 33.2 \text { to } 39.2 \mathrm{MPa} \text { for } 1.5 \% \\
\text { silane), and impact strength increased } \\
\text { from } 16.08 \text { to } 19.34 \mathrm{~kJ} / \mathrm{m}^{2} \text { for loading } \\
\text { silane of } 2.5 \% \text { after which, drop on both } \\
\text { these properties was observed }\end{array}$} & \multirow{2}{*}{$\begin{array}{l}\text { The presence of clay may } \\
\text { act as stress concentrators } \\
\text { under stress hence drasti- } \\
\text { cally reducing mechanical } \\
\text { properties, but the treat- } \\
\text { ment of the WFs can coun- } \\
\text { teract such negative effects. } \\
\text { Flame retardancy can be } \\
\text { improved by the inclusion } \\
\text { of a small amount of clay } \\
(>5 \%) \text {. }\end{array}$} & \multirow[b]{2}{*}{ [27] } \\
\hline $\begin{array}{l}\mathrm{PVC} 100 \%-\mathrm{WF} 70 \mathrm{phr} / 5 \mathrm{phr} \\
\mathrm{Pb} \text { thermal stabilizer/ } 1.5 \mathrm{phr} \\
\text { processing agent, } 5 \mathrm{phr} \text { chlo- } \\
\text { ride polyethylene, } 0.5 \text { to } 4.5\end{array}$ & & & & \\
\hline $\begin{array}{l}\text { PP/WF/MAPP/Antioxidant } \\
101036 / 54 / 9 / 1\end{array}$ & \multirow{4}{*}{$\begin{array}{l}\text { The mixture of CA and } \\
\text { MCA at a ratio of } 5: 1 \text { ex- } \\
\text { hibited the highest LOI } \\
\text { value of } 29.5 \% \text { and passed } \\
\text { the UL- } 94 \text { test as V-0 rat- } \\
\text { ing, and this sample dis- } \\
\text { played the lowest HRR and } \\
\text { THR of } \\
304.1 \mathrm{~kW} / \mathrm{m}^{2} \text { and } \\
97.9 \mathrm{MJ} / \mathrm{m}^{2}\end{array}$} & \multirow{4}{*}{$\begin{array}{l}\text { Similarly, PP/WF/MAPP/Antioxidant } \\
\text { 1010/AP/MCA } 28 / 42 / 9 / 1 / 16.7 / 3.3 \text { dis- } \\
\text { played the highest flexural strength, with } \\
\text { tensile strength being insignificantly de- } \\
\text { creased by about } 3.5 \mathrm{MPa} \text { when com- } \\
\text { pared to neat WPC }\end{array}$} & \multirow{4}{*}{$\begin{array}{l}\text { Synergistic effect between } \\
\text { FRs can promote both } \\
\text { flame retardancy behavior } \\
\text { without compromising me- } \\
\text { chanical properties de- } \\
\text { pending on the functional- } \\
\text { ity of the FRs, which can } \\
\text { promote interfacial adhe- } \\
\text { sion }\end{array}$} & \multirow{4}{*}[22]{} \\
\hline $\begin{array}{l}\text { PP/WF/MAPP/Antioxidant } \\
\text { 1010/AP 28/42/9/1/20 }\end{array}$ & & & & \\
\hline $\begin{array}{l}\text { PP/WF/MAPP/Antioxidant } \\
\text { 1010/MCA 28/42/9/1/20 }\end{array}$ & & & & \\
\hline $\begin{array}{l}\text { PP/WF/MAPP/Antioxidant } \\
\text { 1010/AP/MCA } \\
\text { 28/42/9/1/16.7/3.3 }\end{array}$ & & & & \\
\hline
\end{tabular}


Table 5. Continuous (2).

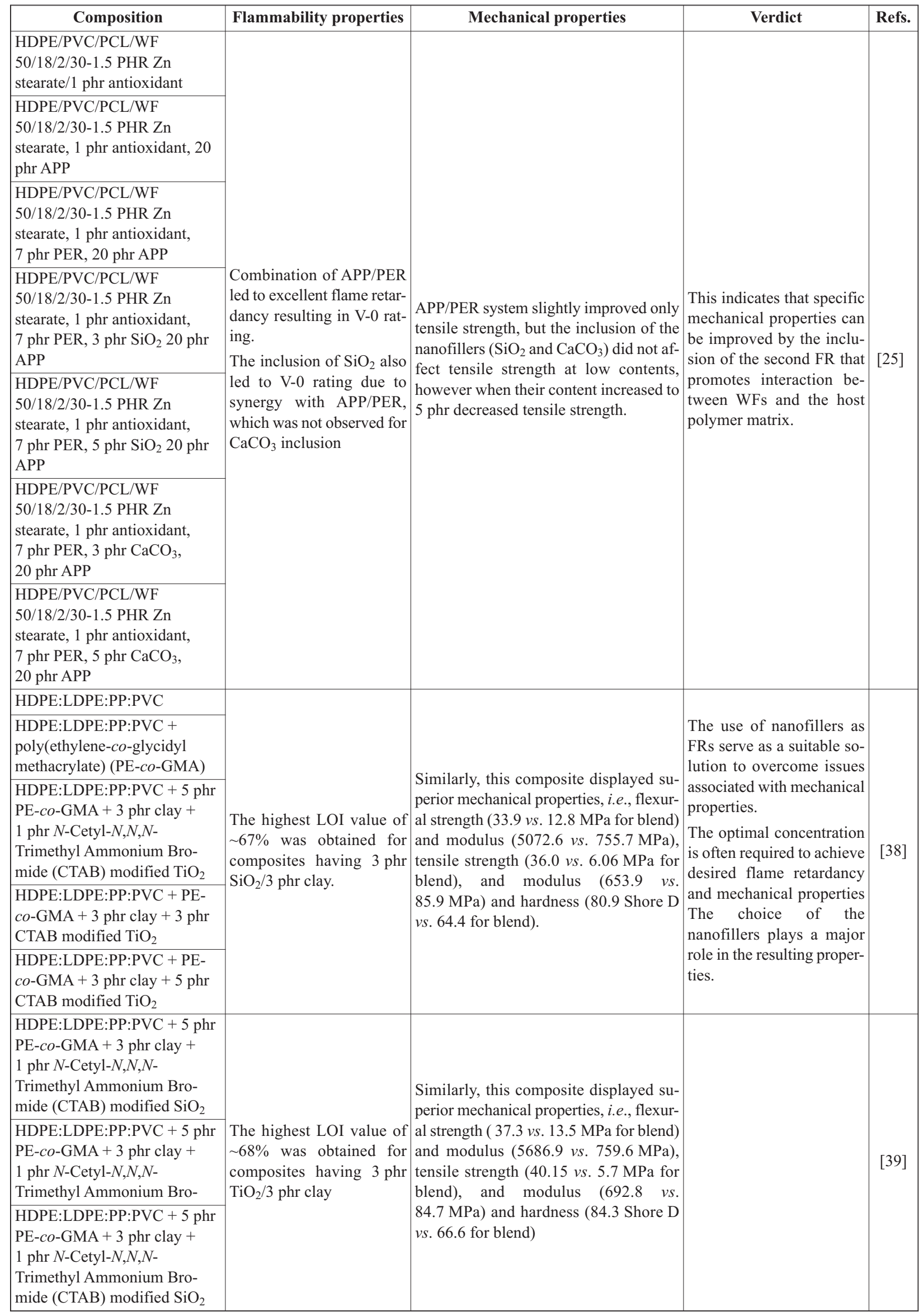


low-cost products are significant needs in the coming years [11]. With the growing demands in the use of recycled polymers, a substitution of virgin materials serves as a suitable solution to reduce the overall cost of the WPC production while protecting the environment [97]. There is limited studies on the use of biodegradable polymers as well as thermosetbased studies on WPCs containing FRs. In the future, we foresee more studies on biodegradable polymers, especially for short-term items, such as flower pots. The production of FRs that improves the interaction between the WFs and hydrophobic polymers is essential to address the compatibility issues. Functionalization of FRs and/or WFs with moieties, which are biocides, antifungal, and UV-resistance, will be the best choice to open doors for WPCs in the near future, especially for interior and exterior applications. The utilization of cheaper and functional nanofillers to compensate most of the properties that are adversely affected, e.g., mechanical and durability by the addition/treatment of WFs with FRs, will no doubt offer new opportunities for WPCs. This includes the use of antifungal, antibacterial, and thermally stable nanofillers to promote durability and other properties without using additional additives, which can result in WPC being suitable for use in high-end applications, e.g., aviation and energy production. The prediction models to correlate the mechanical properties with flame retardancy depending on the properties (e.g., shape, functionality, etc.) of the fillers will offer a novel platform for researchers/engineers to save time and costs.

\section{Conclusions}

This review provides a good guide for the numerous interesting researches on WPCs containing FRs, as a new platform for opportunities in building and automotive applications. It became apparent that the types of flame retardant, polymer matrices, and preparation methods played significant roles in the overall flammability and mechanical properties of woodplastic composites. The processing technique is selected in such a way that WPCs containing additives meet certain criteria on durability, low manufacturing cost, and production rate. It became clear that the most preferred polymer matrices for the formation of WPC are PP and PE. This is because their combustions result in less toxic gases but also due to their low melting temperatures, which are well below the degradation temperatures of WFs. Ammonium phosphate and graphite are two of the most commonly utilized flame retardants, in addition to metal hydroxides, e.g., aluminum hydroxide and magnesium hydroxide. This is due to their high fire resistance efficiencies. Boron-based FRs, however, offer more than other FRs due to their attractive attributes, such as antifungal and antimicrobial properties, with less effect on the mechanical properties; hence, they have been used for a wood preservative. The hygroscopic nature of the most used FRs (e.g., APP) is one of the limiting factors of their use for residential and furniture applications. It is deduced from this review that the use of additional filler/FR can overcome the other FRs' weaknesses to enhance the overall properties of the WPC products.

\section{Acknowledgements}

We are grateful for financial support from the Department of Science and Innovation-National Research Foundation (DSINRF) Innovation Postdoctoral Fellowship, South Africa (Grant UID: 120772)

\section{References}

[1] Ashori A.: Wood-plastic composites as promising green-composites for automotive industries! Bioresource Technology, 99, 4661-4667 (2008). https://doi.org/10.1016/j.biortech.2007.09.043

[2] Naumann A., Seefeldt H., Stephan I., Braun U., Noll M.: Material resistance of flame retarded wood-plastic composites against fire and fungal decay. Polymer Degradation and Stability, 97, 1189-1196 (2012). https://doi.org/10.1016/j.polymdegradstab.2012.03.031

[3] Ansell M. P.: Hybrid wood composites - Integration of wood with other engineering materials. in 'Wood composites' (ed.: Ansell M. P.) Woodhead, Cambridge, 411-426 (2015). https://doi.org/10.1016/B978-1-78242-454-3.00016-0

[4] Turku I., Kärki T.: The effect of carbon fibers, glass fibers and nanoclay on wood flour-polypropylene composite properties. European Journal of Wood and Wood Products, 72, 73-79 (2014).

https://doi.org/10.1007/s00107-013-0754-8

[5] Turku I., Kärki T., Puurtinen A.: Flammability of wood plastic composites prepared from plastic waste. Fire and Materials, 42, 198-201 (2018).

https://doi.org/10.1002/fam.2480

[6] Stark N. M., White R. H., Mueller S. A., Osswald T. A.: Evaluation of various fire retardants for use in wood flour-polyethylene composites. Polymer Degradation and Stability, 95, 1903-1910 (2010).

https://doi.org/10.1016/j.polymdegradstab.2010.04.014 
[7] Li B., He J.: Investigation of mechanical property, flame retardancy and thermal degradation of LLDPE-woodfibre composites. Polymer Degradation and Stability, 83, 241-246 (2004).

https://doi.org/10.1016/S0141-3910(03)00268-4

[8] Agwuncha S. C., Ibrahim I. D., Sadiku E. R.: Improving the thermal and flame resistance properties of polyolefins. in 'Polyolefin fibres: Structure, properties and industrial applications' (ed.: Ugbolue S. C. O.) Woodhead, Duxford, 421-448 (2017).

https://doi.org/10.1016/B978-0-08-101132-4.00014-X

[9] Schirp A., Su S.: Effectiveness of pre-treated wood particles and halogen-free flame retardants used in wood-plastic composites. Polymer Degradation and Stability, 126, 81-92 (2016).

https://doi.org/10.1016/j.polymdegradstab.2016.01.016

[10] Yang Y., Haurie L., Wen J., Zhang S., Ollivier A., Wang D-Y.: Effect of oxidized wood flour as functional filler on the mechanical, thermal and flame-retardant properties of polylactide biocomposites. Industrial Crops and Products, 130, 301-309 (2019).

https://doi.org/10.1016/j.indcrop.2018.12.090

[11] Spear M. J., Eder A., Carus M.: Wood polymer composites. in 'Wood composites' (eds.: Ansell M. P.) Woodhead, Cambridge, 195-249 (2015). https://doi.org/10.1016/B978-1-78242-454-3.00010-X

[12] Zandi M. D., Jerez-Mesa R., Lluma-Fuentes J., JorbaPeiro J., Travieso-Rodriguez J. A.: Study of the manufacturing process effects of fused filament fabrication and injection molding on tensile properties of composite PLA-wood parts. The International Journal of Advanced Manufacturing Technology, 108, 1725-1735 (2020) https://doi.org/10.1007/s00170-020-05522-4

[13] Zandi M. D., Jerez-Mesa R., Lluma-Fuentes J., Roa J. J., Travieso-Rodriguez J. A.: Experimental analysis of manufacturing parameters' effect on the flexural properties of wood-PLA composite parts built through FFF. The International Journal of Advanced Manufacturing Technology, 106, 3985-3998 (2020).

https://doi.org/10.1007/s00170-019-04907-4

[14] Travieso-Rodriguez J. A., Zandi M. D., Jerez-Mesa R., Lluma-Fuentes J.: Fatigue behavior of PLA-wood composite manufactured by fused filament fabrication. Journal of Materials Research and Technology, 9, 8507 8516 (2020). https://doi.org/10.1016/j.jmrt.2020.06.003

[15] Partanen A., Carus M.: Wood and natural fiber composites current trend in consumer goods and automotive parts. Reinforced Plastics, 60, 170-173 (2016). https://doi.org/10.1016/j.repl.2016.01.004

[16] Salmeia K. A., Fage J., Liang S., Gaan S.: An overview of mode of action and analytical methods for evaluation of gas phase activities of flame retardants. Polymers, 7, 504-526 (2015).

https://doi.org/10.3390/polym7030504
[17] Stark N. M., Mueller S. A., White R. H., Osswald T. A.: Effect of fire retardants on heat release rate of wood flour-polyethylene composites. in ' $10^{\text {th }}$ International Conference on Wood and Biofiber Plastic Composite and Cellulose Nanocomposites Symposium. Madison, USA' 103-109 (2009).

[18] Zong G., Hao J., Hao X., Fang Y., Song Y., Wang H., Ou R., Wang Q.: Enhancing the flame retardancy and mechanical properties of veneered wood flour/polyvinyl chloride composites. Polymer Composites, 41, 848-857 (2020). https://doi.org/10.1002/pc.25415

[19] Morgan A. B., Gilman J. W.: An overview of flame retardancy of polymeric materials: Application, technology, and future directions. Fire and Materials, 37, 259279 (2013). https://doi.org/10.1002/fam.2128

[20] Bledzki A. K., Letman M., Viksne A., Rence L.: A comparison of compounding processes and wood type for wood fibre-PP composites. Composites Part A: Applied Science and Manufacturing, 36, 789-797 (2005). https://doi.org/10.1016/j.compositesa.2004.10.029

[21] Carus M., Gahle C., Korte H.: Market and future trends for wood-polymer composites in Europe: The example of Germany. in 'Wood-polymer composites' (eds.: Niska K. O., Sain M.) Woodhead, Cambridge, 300330 (2008).

https://doi.org/10.1533/9781845694579.300

[22] Zhao P., Guo C., Li L.: Flame retardancy and thermal degradation properties of polypropylene/wood flour composite modified with aluminum hypophosphite/ melamine cyanurate. Journal of Thermal Analysis and Calorimetry, 135, 3085-3093 (2019). https://doi.org/10.1007/s10973-018-7544-9

[23] Ayrilmis N., Akbulut T., Dundar T., White R. H., Mengeloglu F., Buyuksari U., Candan Z., Avci E.: Effect of boron and phosphate compounds on physical, mechanical, and fire properties of wood-polypropylene composites. Construction and Building Materials, 33, 63-69 (2012).

https://doi.org/10.1016/j.conbuildmat.2012.01.013

[24] Jiang S., Yang Y., Ge S., Zhang Z., Peng W.: Preparation and properties of novel flame-retardant PBS woodplastic composites. Arabian Journal of Chemistry, 11, 844-857 (2018). https://doi.org/10.1016/j.arabjc.2017.12.023

[25] Krehula L. K., Katančić Z., Marić G., Hrnjak-Murgić Z.: Study of fire retardancy and thermal and mechanical properties of HDPE-wood composites. Journal of Wood Chemistry and Technology, 35, 412-423 (2015). https://doi.org/10.1080/02773813.2015.1011277

[26] Ustaomer D., Usta M.: The effects of boron compounds and different melamine contents in MUF resins on some properties of MDF panels. BioResources, 7, 437-446 (2012). 
[27] Zhao Y., Wang K., Zhu F., Xue P., Jia M.: Properties of poly(vinyl chloride)/wood flour/montmorillonite composites: Effects of coupling agents and layered silicate. Polymer Degradation and Stability, 91, 2874 2883 (2006). https://doi.org/10.1016/j.polymdegradstab.2006.09.001

[28] Li X., Liang D., Li K., Ma X., Cui J., Hu Z.: Synergistic effect of a hypophosphorous acid-based ionic liquid and expandable graphite on the flame-retardant properties of wood-plastic composites. Journal of Thermal Analysis and Calorimetry, in press (2021). https://doi.org/10.1007/s10973-020-09781-x

[29] Ayrilmis N., Benthien J. T., Thoemen H., White R. H.: Effects of fire retardants on physical, mechanical, and fire properties of flat-pressed WPCs. European Journal of Wood and Wood Products, 70, 215-224 (2012). https://doi.org/10.1007/s00107-011-0541-3

[30] Kong F-B., He Q-L., Peng W., Nie S-B., Dong X., Yang J-N.: Eco-friendly flame retardant poly(lactic acid) composites based on banana peel powders and phytic acid: Flame retardancy and thermal property. Journal of Polymer Research, 27, 204/1-204/12 (2020). https://doi.org/10.1007/s10965-020-02176-4

[31] Ratanawilai T., Taneerat K.: Alternative polymeric matrices for wood-plastic composites: Effects on mechanical properties and resistance to natural weathering. Construction and Building Materials, 172, 349-357 (2018). https://doi.org/10.1016/j.conbuildmat.2018.03.266

[32] Cavdar A. D., Mengeloğlu F., Karakus K.: Effect of boric acid and borax on mechanical, fire and thermal properties of wood flour filled high density polyethylene composites. Measurement, 60, 6-12 (2015). https://doi.org/10.1016/j.measurement.2014.09.078

[33] Wang Y., Simonsen J., Neto C. P., Rocha J., Rials T. G., Hart E.: The reaction of boric acid with wood in a polystyrene matrix. Journal of Applied Polymer Science, 62, 501-508 (1996).

https://doi.org/10.1002/(SICI)10974628(19961017)62:3<501::AID-APP8>3.0.CO;2-U

[34] Sun L., Wu Q., Xie Y., Cueto R., Lee S., Wang Q.: Thermal degradation and flammability behavior of fire-retarded wood flour/polypropylene composites. Journal of Fire Sciences, 34, 226-239 (2016). https://doi.org/10.1177/0734904116637632

[35] Xu B-R., Deng C., Li Y-M., Lu P., Zhao P-P., Wang Y-Z.: Novel amino glycerin decorated ammonium polyphosphate for the highly-efficient intumescent flame retardance of wood flour/polypropylene composite via simultaneous interfacial and bulk charring. Composites Part B: Engineering, 172, 636-648 (2019). https://doi.org/10.1016/j.compositesb.2019.05.099

[36] García M., Hidalgo J., Garmendia I., García-Jaca J.: Wood-plastics composites with better fire retardancy and durability performance. Composites Part A: Applied Science and Manufacturing, 40, 1772-1776 (2009).

https://doi.org/10.1016/j.compositesa.2009.08.010
[37] Lim K-S., Bee S-T., Sin L. T., Tee T-T., Ratnam C. T., Hui D., Rahmat A. R.: A review of application of ammonium polyphosphate as intumescent flame retardant in thermoplastic composites. Composites Part B: Engineering, 84, 155-174 (2016).

https://doi.org/10.1016/j.compositesb.2015.08.066

[38] Deka B. K., Maji T. K.: Effect of $\mathrm{TiO}_{2}$ and nanoclay on the properties of wood polymer nanocomposite. Composites Part A: Applied Science and Manufacturing, 42, 2117-2125 (2011).

https://doi.org/10.1016/j.compositesa.2011.09.023

[39] Deka B. K., Maji T. K.: Effect of $\mathrm{SiO}_{2}$ and nanoclay on the properties of wood polymer nanocomposite. Polymer Bulletin, 70, 403-417 (2013). https://doi.org/10.1007/s00289-012-0799-6

[40] Liang C., Yang B., Wang D., Chen J., Huang Y., Chen Z., Miao J., Qian J., Xia R., Tu Y., Shi Y., Chen P.: Investigation of the properties of polystyrene-based wood plastic composites: Effects of the flame retardant loading and magnetic fields. Journal of Polymer Engineering, 39, 704-715 (2019).

https://doi.org/10.1515/polyeng-2019-0079

[41] Zhou H., Hao X., Wang X., Liu T., Sun L., Yi X., Wang Q., Ou R.: Comparative study on the effects of silica size and dispersion mode on the fire retardancy of extruded wood fiber/HDPE composites. Polymer Composites, 41, 4920-4932 (2020). https://doi.org/10.1002/pc.25763

[42] Khalili P., Tshai K. Y., Kong I.: Natural fiber reinforced expandable graphite filled composites: Evaluation of the flame retardancy, thermal and mechanical performances. Composites Part A: Applied Science and Manufacturing, 100, 194-205 (2017).

https://doi.org/10.1016/j.compositesa.2017.05.015

[43] Salasinska K., Mizera K., Barczewski M., Borucka M., Gloc M., Celiński M., Gajek A.: The influence of degree of fragmentation of Pinus sibirica on flammability, thermal and thermomechanical behavior of the epoxy-composites. Polymer Testing, 79, 106036/1106036/12 (2019).

https://doi.org/10.1016/j.polymertesting.2019.106036

[44] Patel V. K., Rawat N.: Physico-mechanical properties of sustainable sagwan-teak wood flour/polyester composites with/without gum rosin. Sustainable Materials and Technologies, 13, 1-8 (2017).

https://doi.org/10.1016/j.susmat.2017.05.002

[45] Mochane M. J., Mokhena T. C., Mokhothu T. H., Mtibe A., Sadiku E. R., Ray S. S., Ibrahim I. D., Daramola O. O.: Recent progress on natural fiber hybrid composites for advanced applications: A review. Express Polymer Letters, 13, 159-198 (2019). https://doi.org/10.3144/expresspolymlett.2019.15

[46] Costes L., Laoutid F., Brohez S., Dubois P.: Bio-based flame retardants: When nature meets fire protection. Materials Science and Engineering R: Reports, 17, 125 (2017).

https://doi.org/10.1016/j.mser.2017.04.001 
[47] Kalali E. N., Zhang L., Shabestari M. E., Croyal J., Wang D-Y.: Flame-retardant wood polymer composites (WPCs) as potential fire safe bio-based materials for building products: Preparation, flammability and mechanical properties. Fire Safety Journal, 107, 210 216 (2019). https://doi.org/10.1016/j.firesaf.2017.11.001

[48] Yang H., Yu B., Xu X., Bourbigot S., Wang H., Song P.: Lignin-derived bio-based flame retardants toward high-performance sustainable polymeric materials. Green Chemistry, 22, 2129-2161 (2020). https://doi.org/10.1039/D0GC00449A

[49] Zhang Z. X., Zhang J., Lu B-X., Xin Z. X., Kang C. K., Kim J. K.: Effect of flame retardants on mechanical properties, flammability and foamability of PP/woodfiber composites. Composites Part B: Engineering, 43, 150-158 (2012). https://doi.org/10.1016/j.compositesb.2011.06.020

[50] Pham L. H., Nguyen H. D., Kim J., Hoang D.: Thermal properties and fire retardancy of polypropylene/wood flour composites containing eco-friendly flame retardants. Fibers and Polymers, 20, 2383-2389 (2019). https://doi.org/10.1007/s12221-019-1179-8

[51] Hu W., Zhang Y., Qi Y., Wang H., Liu B., Zhao Q., Zhang J., Duan J., Zhang L., Sun Z., Liu B.: Improved mechanical properties and flame retardancy of wood/ PLA all-degradable biocomposites with novel ligninbased flame retardant and TGIC. Macromolecular Materials and Engineering, 305, 1900840/1-1900840/10 (2020).

https://doi.org/10.1002/mame.201900840

[52] Seefeldt H., Braun U.: Burning behavior of wood-plastic composite decking boards in end-use conditions: The effects of geometry, material composition, and moisture. Journal of Fire Sciences, 30, 41-54 (2011). https://doi.org/10.1177/0734904111423488

[53] Riva A., Camino G., Fomperie L., Amigouët P.: Fire retardant mechanism in intumescent ethylene vinyl acetate compositions. Polymer Degradation and Stability, 82, 341-346 (2003). https://doi.org/10.1016/S0141-3910(03)00191-5

[54] Arao Y., Nakamura S., Tomita Y., Takakuwa K., Umemura T., Tanaka T.: Improvement on fire retardancy of wood flour/polypropylene composites using various fire retardants. Polymer Degradation and Stability, 100, 79-85 (2014). https://doi.org/10.1016/j.polymdegradstab.2013.12.022

[55] Wu Z., Hu N., Wu Y., Wu S., Qin Z.: The effect of ultrafine magnesium hydroxide on the tensile properties and flame retardancy of wood plastic composites. Journal of Nanomaterials, 2014, 945308/1-945308/12 (2014). https://doi.org/10.1155/2014/945308

[56] Umemura T., Arao Y., Nakamura S., Tomita Y., Tanaka T.: Synergy effects of wood flour and fire retardants in flammability of wood-plastic composites. Energy Procedia, 56, 48-56 (2014).

https://doi.org/10.1016/j.egypro.2014.07.130
[57] Uddin M., Kiviranta K., Suvanto S., Alvila L., Leskinen J., Lappalainen R., Haapala A.: Casein-magnesium composite as an intumescent fire retardant coating for wood. Fire Safety Journal, 112, 102943/1-102943/7 (2020). https://doi.org/10.1016/j.firesaf.2019.102943

[58] Phan H. T. Q., Nguyen B. T., Pham L. H., Pham C. T., Do T. V., Hoang C. N., Nguyen N. N., Kim J., Hoang D.: Excellent fireproof characteristics and high thermal stability of rice husk-filled polyurethane with halogenfree flame retardant. Polymers, 11, 1587/1-1587/17 (2019).

https://doi.org/10.3390/polym11101587

[59] Zhang J., Mei C., Huang R., Xu X., Lee S., Kim B-J., Wu Q.: Comparative mechanical, fire-retarding, and morphological properties of high-density polyethylene/(wood flour) composites with different flame retardants. Journal of Vinyl and Additive Technology, 24, 3-12 (2018).

https://doi.org/10.1002/vnl.21516

[60] Pham L. H., Pham L. T., Hoang D., Kim J.: Effective phosphorus/phosphorus-nitrogen fire retardants applied to biocomposites based on polypropylene-wood flour: Flammability, thermal behavior, and mechanical properties. Macromolecular Research, 27, 1185-1192 (2019). https://doi.org/10.1007/s13233-019-7167-4

[61] Hoang D., Pham T., Nguyen T., An H., Kim J.: Organophosphorus flame retardants for poly(vinyl chloride)/ wood flour composite. Polymer Composites, 39, 961970 (2018).

https://doi.org/10.1002/pc.24026

[62] Pan M., Mei C., Du J., Li G.: Synergistic effect of nano silicon dioxide and ammonium polyphosphate on flame retardancy of wood fiber-polyethylene composites. Composites Part A: Applied Science and Manufacturing, 66, 128-134 (2014). https://doi.org/10.1016/j.compositesa.2014.07.016

[63] Li L., Guo W., Guo C.: Synergistic effect of melamine polyphosphate and aluminum hypophosphite on mechanical properties and flame retardancy of HDPE/ wood flour composites. Wood Science and Technology, 51, 493-506 (2017). https://doi.org/10.1007/s00226-016-0877-2

[64] Guan Y-H., Huang J-Q., Yang J-C., Shao Z-B., Wang Y-Z.: An effective way to flame-retard biocomposite with ethanolamine modified ammonium polyphosphate and its flame retardant mechanisms. Industrial and Engineering Chemistry Research, 54, 3524-3531 (2015). https://doi.org/10.1021/acs.iecr.5b00123

[65] Chindaprasirt P., Hiziroglu S., Waisurasingha C., Kasemsiri P.: Properties of wood flour/expanded polystyrene waste composites modified with diammonium phosphate flame retardant. Polymer Composites, 36, 604-612 (2015).

https://doi.org/10.1002/pc.22977 
[66] Cheng X-W., Tang R-C., Yao F., Yang X-H.: Flame retardant coating of wool fabric with phytic acid/polyethyleneimine polyelectrolyte complex. Progress in Organic Coatings, 132, 336-342 (2019).

https://doi.org/10.1016/j.porgcoat.2019.04.018

[67] Nie S., Jin D., Yang J-N., Dai G., Luo Y.: Fabrication of environmentally-benign flame retardant cotton fabrics with hydrophobicity by a facile chemical modification. Cellulose, 26, 5147-5158 (2019). https://doi.org/10.1007/s10570-019-02431-y

[68] Laufer G., Kirkland C., Morgan A. B., Grunlan J. C.: Intumescent multilayer nanocoating, made with renewable polyelectrolytes, for flame-retardant cotton. Biomacromolecules, 13, 2843-2848 (2012).

https://doi.org/10.1021/bm300873b

[69] Terzi E., Kartal S. N., Piskin S., Stark N., Figen A. K., White R. H.: Colemanite: A fire retardant candidate for wood plastic composites. BioResources, 13, 1491-1509 (2018).

[70] Fang Y., Wang Q., Guo C., Song Y., Cooper P. A.: Effect of zinc borate and wood flour on thermal degradation and fire retardancy of polyvinyl chloride (PVC) composites. Journal of Analytical and Applied Pyrolysis, 100, 230-236 (2013).

https://doi.org/10.1016/j.jaap.2012.12.028

[71] Seefeldt H., Braun U., Wagner M. H.: Residue stabilization in the fire retardancy of wood-plastic composites: Combination of ammonium polyphosphate, expandable graphite, and red phosphorus. Macromolecular Chemistry and Physics, 213, 2370-2377 (2012). https://doi.org/10.1002/macp.201200119

[72] Guo C., Zhou L., Lv J.: Effects of expandable graphite and modified ammonium polyphosphate on the flameretardant and mechanical properties of wood flourpolypropylene composites. Polymers and Polymer Composites, 21, 449-456 (2013). https://doi.org/10.1177/096739111302100706

[73] Zheng J., Li B., Guo C., Wu Q., Wang Y.: Flame-retardant properties of acrylonitrile-butadiene-styrene/ wood flour composites filled with expandable graphite and ammonium polyphosphate. Journal of Applied Polymer Science, 131, 40281/1-40281/6 (2014). https://doi.org/10.1002/app.40281

[74] Chun K., Kim J., Rie D.: Thermal characteristics of expandable graphite-wood particle composites. Materials, 13, 2732/1-2732/18 (2020). https://doi.org/10.3390/ma13122732

[75] Sun L., Wu Q., Xie Y., Wang F., Wang Q.: Thermal degradation and flammability properties of multilayer structured wood fiber and polypropylene composites with fire retardants. RSC Advances, 6, 13890-13897 (2016).

https://doi.org/10.1039/C5RA23262G
[76] Yu F., Xu F., Song Y., Fang Y., Zhang Z., Wang Q., Wang F.: Expandable graphite's versatility and synergy with carbon black and ammonium polyphosphate in improving antistatic and fire-retardant properties of wood flour/polypropylene composites. Polymer Composites, 38, 767-773 (2017).

https://doi.org/10.1002/pc.23636

[77] Zhou H., Xiao Z., Wang Y., Hao X., Xie Y., Song Y., Wang F., Wang Q.: Conductive and fire-retardant wood/ polyethylene composites based on a continuous honeycomb-like nanoscale carbon black network. Construction and Building Materials, 233, 117369/1117369/8 (2020).

https://doi.org/10.1016/j.conbuildmat.2019.117369

[78] Turku I., Kärki T.: The influence of carbon-based fillers on the flammability of polypropylene-based coextruded wood-plastic composite. Fire and Materials, 40, 498-506 (2016).

https://doi.org/10.1002/fam.2306

[79] Cipiriano B. H., Kashiwagi T., Raghavan S. R., Yang Y., Grulke E. A., Yamamoto K., Shields J. R., Douglas J. F.: Effects of aspect ratio of MWNT on the flammability properties of polymer nanocomposites. Polymer, 48, 6086-6096 (2007).

https://doi.org/10.1016/j.polymer.2007.07.070

[80] Sheshmani S., Ashori A., Fashapoyeh M. A.: Wood plastic composite using graphene nanoplatelets. International Journal of Biological Macromolecules, 58, 16 (2013).

https://doi.org/10.1016/j.ijbiomac.2013.03.047

[81] Huang R., Zhang X., Chen Z., Wan M., Wu Q.: Thermal stability and flame resistance of the coextruded wood-plastic composites containing talc-filled plastic shells. International Journal of Polymer Science, 2020, 1435249/1-1435249/9 (2020). https://doi.org/10.1155/2020/1435249

[82] Liu L., Qian M., Song P., Huang G., Yu Y., Fu S.: Fabrication of green lignin-based flame retardants for enhancing the thermal and fire retardancy properties of polypropylene/wood composites. ACS Sustainable Chemistry and Engineering, 4, 2422-2431 (2016). https://doi.org/10.1021/acssuschemeng.6b00112

[83] Kausar A.: Flame retardant potential of clay nanoparticles. in 'Clay nanoparticles' (eds.: Cavallaro G., Fakhrullin R., Pasbakhsh P.) Elsevier, Amsterdam, 169-184 (2020). https://doi.org/10.1016/B978-0-12-816783-0.00007-4

[84] Giri R., Nayak L., Rahaman M.: Flame and fire retardancy of polymer-based composites. Materials Research Innovations, 25, 1-29 (2020). https://doi.org/10.1080/14328917.2020.1728073

[85] Lee Y. H., Kuboki T., Park C. B., Sain M.: The effects of nanoclay on the extrusion foaming of wood fiber/ polyethylene nanocomposites. Polymer Engineering and Science, 51, 1014-1022 (2011). https://doi.org/10.1002/pen.21739 
[86] Guo G., Park C. B., Lee Y. H., Kim Y. S., Sain M.: Flame retarding effects of nanoclay on wood-fiber composites. Polymer Engineering and Science, 47, 330 336 (2007).

https://doi.org/10.1002/pen.20712

[87] Lee Y. H., Kuboki T., Park C. B., Sain M., Kontopoulou M.: The effects of clay dispersion on the mechanical, physical, and flame-retarding properties of wood fiber/polyethylene/clay nanocomposites. Journal of Applied Polymer Science, 118, 452-461 (2010). https://doi.org/10.1002/app.32045

[88] Zhou H., Wang X., Hao X., Wang Q., Ou R.: Mechanical properties and fire retardancy of wood flour/highdensity polyethylene composites reinforced with continuous honeycomb-like nano- $\mathrm{SiO}_{2}$ network and fire retardant. Journal of Renewable Materials, 8, 485-498 (2020). https://doi.org/10.32604/jrm.2020.010263

[89] Ding C., Pan M., Chen H., Zhang S., Mei C.: An anionic polyelectrolyte hybrid for wood-polyethylene composites with high strength and fire safety via selfassembly. Construction and Building Materials, 248, 118661/1-118661/12 (2020) https://doi.org/10.1016/j.conbuildmat.2020.118661

[90] Wang W., Peng Y., Zammarano M., Zhang W., Li J.: Effect of ammonium polyphosphate to aluminum hydroxide mass ratio on the properties of wood-flour/ polypropylene composites. Polymers, 9, 615/1-615/16 (2017). https://doi.org/10.3390/polym9110615

[91] Wang W., Zhang W., Chen H., Zhang S., Li J.: Synergistic effect of synthetic zeolites on flame-retardant wood-flour/polypropylene composites. Construction and Building Materials, 79, 337-344 (2015). https://doi.org/10.1016/j.conbuildmat.2015.01.038

[92] Sun L., Xie Y., Ou R., Guo C., Hao X., Wu Q., Wang Q.: The influence of double-layered distribution of fire retardants on the fire retardancy and mechanical properties of wood fiber polypropylene composites. Construction and Building Materials, 242, 118047/1118047/8 (2020). https://doi.org/10.1016/j.conbuildmat.2020.118047

[93] Ren Y., Wang Y., Wang L., Liu T.: Evaluation of intumescent fire retardants and synergistic agents for use in wood flour/recycled polypropylene composites. Construction and Building Materials, 76, 273-278 (2015). https://doi.org/10.1016/j.conbuildmat.2014.12.004

[94] Zhang Q., Cai H., Yang K., Yi W.: Effect of biochar on mechanical and flame retardant properties of wood plastic composites. Results in Physics, 7, 2391-2395 (2017). https://doi.org/10.1016/j.rinp.2017.04.025

[95] Balasuriya P. W., Ye L., Mai Y-W.: Mechanical properties of wood flake-polyethylene composites. Part I: Effects of processing methods and matrix melt flow behaviour. Composites Part A: Applied Science and Manufacturing, 32, 619-629 (2001) https://doi.org/10.1016/S1359-835X(00)00160-3
[96] Hamid M. R. Y., Ab Ghani M. H., Ahmad S.: Effect of antioxidants and fire retardants as mineral fillers on the physical and mechanical properties of high loading hybrid biocomposites reinforced with rice husks and sawdust. Industrial Crops and Products, 40, 96-102 (2012). https://doi.org/10.1016/j.indcrop.2012.02.019

[97] Sain M., Park S. H., Suhara F., Law S.: Flame retardant and mechanical properties of natural fibre-PP composites containing magnesium hydroxide. Polymer Degradation and Stability, 83, 363-367 (2004). https://doi.org/10.1016/S0141-3910(03)00280-5

[98] Ayrilmis N.: Combined effects of boron and compatibilizer on dimensional stability and mechanical properties of wood/HDPE composites. Composites Part B: Engineering, 44, 745-749 (2013). https://doi.org/10.1016/j.compositesb.2012.04.002

[99] Kurt R., Mengeloğlu F.: Utilization of boron compounds as synergists with ammonium polyphosphate for flame retardant wood-polymer composites. Turkish Journal of Agriculture and Forestry, 35, 155-163 (2011).

[100] Mngomezulu M. E., John M. J., Jacobs V., Luyt A. S.: Review on flammability of biofibres and biocomposites. Carbohydrate Polymers, 111, 149-182 (2014). https://doi.org/10.1016/j.carbpol.2014.03.071

[101] Guan Y-H., Liao W., Xu Z-Z., Chen M-J., Huang J-Q., Wang Y-Z.: Improvement of the flame retardancy of wood-fibre/polypropylene composites with ideal mechanical properties by a novel intumescent flame retardant system. RSC Advances, 5, 59865-59873 (2015). https://doi.org/10.1039/C5RA08292G

[102] Ramli R. A., Zakaria N. Z., Rahman U. U. A., Bakhtiar N. B. A., Mustapha S. N. H., Lian Y. M.: Effect of mineral fillers on mechanical, thermal and morphological properties of kenaf recycled polyethylene wood plastic composite. European Journal of Wood and Wood Products, 76, 1737-1743 (2018). https://doi.org/10.1007/s00107-018-1356-2

[103] Sommerhuber P. F., Welling J., Krause A.: Substitution potentials of recycled HDPE and wood particles from post-consumer packaging waste in wood-plastic composites. Waste Management, 46, 76-85 (2015). https://doi.org/10.1016/j.wasman.2015.09.011

[104] Najafi S. K.: Use of recycled plastics in wood plastic composites - A review. Waste Management, 33, 18981905 (2013) https://doi.org/10.1016/j.wasman.2013.05.017

[105] Ghalehno M. D., Kord B.: Preparation, characterization and performance evaluation of wood flour/HDPE foamed composites reinforced with graphene nanoplatelets. Journal of Composite Materials, 55, 531-540 (2020). https://doi.org/10.1177/0021998320954527 
[106] Ghasemi I., Farsheh A. T., Masoomi Z.: Effects of multi-walled carbon nanotube functionalization on the morphological and mechanical properties of nanocomposite foams based on poly(vinyl chloride)/(wood flour)/(multi-walled carbon nanotubes). Journal of Vinyl and Additive Technology, 18, 161-167 (2012). https://doi.org/10.1002/vnl.20299

[107] Kordkheili H. Y., Farsi M., Rezazadeh Z.: Physical, mechanical and morphological properties of polymer composites manufactured from carbon nanotubes and wood flour. Composites Part B: Engineering, 44, 750 755 (2013).

https://doi.org/10.1016/j.compositesb.2012.04.023

[108] Li X., Lei B., Lin Z., Huang L., Tan S., Cai X.: The utilization of bamboo charcoal enhances wood plastic composites with excellent mechanical and thermal properties. Materials and Design, 53, 419-424 (2014). https://doi.org/10.1016/j.matdes.2013.07.028

[109] Das O., Sarmah A. K., Bhattacharyya D.: A novel approach in organic waste utilization through biochar addition in wood/polypropylene composites. Waste Management, 38, 132-140 (2015).

https://doi.org/10.1016/j.wasman.2015.01.015

[110] Baysal E., Yalinkilic M. K., Altinok M., Sonmez A., Peker H., Colak M.: Some physical, biological, mechanical, and fire properties of wood polymer composite (WPC) pretreated with boric acid and borax mixture. Construction and Building Materials, 21, 1879 1885 (2007).

https://doi.org/10.1016/j.conbuildmat.2006.05.026
[111] Vedrtnam A., Kumar S., Chaturvedi S.: Experimental study on mechanical behavior, biodegradability, and resistance to natural weathering and ultraviolet radiation of wood-plastic composites. Composites Part B: Engineering, 176, 107282/1-107282/13 (2019). https://doi.org/10.1016/j.compositesb.2019.107282

[112] Islam M. S., Hamdan S., Hasan M., Ahmed A. S., Rahman M. R.: Effect of coupling reactions on the mechanical and biological properties of tropical wood polymer composites (WPC). International Biodeterioration and Biodegradation, 72, 108-113 (2012). https://doi.org/10.1016/j.ibiod.2012.05.019

[113] Spear M. J.: Preservation, protection and modification of wood composites. in 'Wood composites' (ed.: Ansell M. P.) Woodhead, Cambridge, 253-310 (2015).

[114] Hemmati F., Garmabi H.: A study on fire retardancy and durability performance of bagasse fiber/polypropylene composite for outdoor applications. Journal of Thermoplastic Composite Materials, 26, 1041-1056 (2012). https://doi.org/10.1177/0892705711433350

[115] Friedrich D.: Effects from natural weathering on longterm structural performance of wood-polymer composite cladding in the building envelope. Journal of Building Engineering, 23, 68-76 (2019). https://doi.org/10.1016/j.jobe.2019.01.025 